\title{
Políticas ante la fragmentación del mapa municipal*
}

\author{
Fernando López Ramón \\ Universidad de Zaragoza \\ flopez@unizar.es
}

Recibido: 24 de mayo de 2011

Aceptado: 24 de octubre de 2011

Resumen

Partiendo de la notable fragmentación del mapa municipal español en el contexto europeo, se ofrecen elementos estadísticos, históricos y comparados que podrían proporcionar los siguientes criterios de reforma: 1) las diferencias existentes entre los mapas municipales de las Comunidades Autónomas justifican políticas no coincidentes; 2) el tamaño importa, de manera que, distanciándose tanto de posturas inmovilistas como de opciones por la movilidad constante en la organización territorial, cabría establecer un tamaño mínimo de los municipios en la legislación básica del Estado sin perjuicio del diseño de tamaños óptimos por las Comunidades Autónomas; 3) la cooperación intermunicipal como alternativa a las fusiones de municipios requiere esfuerzos sostenidos en el tiempo, y presenta notas de complejidad y de confusión de responsabilidades, según se advierte en el caso de Francia; 4) las fusiones municipales determinadas por fines de equilibrio territorial pueden ser más útiles que las establecidas por razones de eficiencia económica, tal y como ponen de relieve las experiencias europeas de Suecia, Dinamarca, Bélgica y Grecia; y 5) las comarcas como vía alternativa de solución del inframunicipalismo presentan limitaciones, aunque no habría de descartarse el empleo de mapas comarcales para constituir nuevos mapas municipales.

Palabras clave Mapa municipal, pequeños municipios, fusiones de municipios, cooperación intermunicipal, comarcas, entes locales intermedios.

\section{Policies to face the fragmentation of the municipal map}

\begin{abstract}
Starting from the remarkable fragmentation of the Spanish municipal map within the European context, the work presents statistical, historical and comparative information that provide the following criteria for a reform: 1) the differences between regions justify different local policies; 2) size matters are important, so, far away from extremist positions (ie immobilism, on the one hand, and constant reshape of municipalities, on the other), a minimum size for municipalities shall be determined by the basic State law, without prejudice to the design of optimal sizes by the Autonomous Regions in their respective territories; 3) intermunicipal cooperation as an alternative to mergers between municipalities requires sustained efforts over time, and is subject to complexity and confusion of responsibilities, as the French experience shows; 4) municipal mergers motivated by objectives of territorial balance may be more useful than those originated by reasons of economic efficiency, as is highlighted in the experience of Sweden, Denmark, Belgium and Greece; and 5)) counties ("comarcas") as an alternative way of dealing with the problem of infra-size of municipalities have their limitations, although the use of county maps to establish new municipal maps should not be discarded.
\end{abstract}

Keywords

Local map, small municipalities, merger of municipalities, intermunicipal cooperation, counties as intermediate local powers.

* Texto de la ponencia defendida en el “Congreso sobre Organización Local: Nuevos Modelos" organizado por la Cátedra de Derecho Local de Aragón (Gobierno de Aragón y Universidad de Zaragoza) los días 4 y 5 de abril de 2011. 
El objeto de este trabajo es plantear la problemática derivada de la elevada presencia de pequeños municipios en España e identificar las vías de actuación que cabe diseñar para una más adecuada organización del territorio. Comenzaremos exponiendo cómo son los mapas municipales en el nivel estatal y en el autonómico comparándolos con los correspondientes a otros Estados de la Unión Europea. En segundo lugar, reflexionaremos sobre la importancia que cabe conceder al pequeño tamaño de los entes públicos a fin de determinar cuándo habría de tratarse realmente como un problema de la organización territorial. Tercero, nos detendremos en la solución francesa consistente en incrementar la cooperación intermunicipal. Cuarto, referiremos la vía de las fusiones de municipios, exponiendo el alcance de los intentos planteados en nuestra historia y de las políticas de fusión obligatoria de municipios desarrolladas en diversos países europeos. En quinto término, nos ocuparemos de la constitución de comarcas como nuevos entes locales intermedios para remediar las limitadas capacidades de los pequeños municipios. Y por último, dedicaremos el sexto epígrafe a algunas reflexiones sobre la necesidad de insertar la reforma del mapa municipal en un contexto de consolidación de la autonomía local y de medidas de corrección de los desequilibrios territoriales.

\section{EL MAPA MUNICIPAL ESPAÑOL EN EL CONTEXTO EUROPEO}

La escasa población de muchos municipios españoles es un dato sobradamente conocido cuyo recordatorio ha de constituir nuestro punto de partida. Así, según datos del año 2010, existen 8.108 municipios con una población media de 5.765 habitantes/municipio, computándose 6.948 municipios de menos de 5.000 habitantes (85'7\% del total) y nada menos que 981 municipios de población inferior a 100 habitantes (12'09\% del total).

En la tabla A podrá observarse para cada Comunidad Autónoma su población total, número de municipios, así como el cálculo de la población y la superficie medias por municipio. La población media varía notablemente en función de la Comunidad Autónoma, llegando a ser, con respecto a la cifra estatal, 6'18 veces superior en Madrid (35.681 habitantes/municipio), y 5’07 veces inferior en Castilla y León (1.135 habitantes/municipio), con altas diferencias entre Comunidades Autónomas (la población media de los municipios de Madrid supera 31'43 veces la de Castilla y León o 19'39 veces la de Aragón). La comparación de la superficies medias manifiesta también diferencias en los municipios, aunque no tan acentuadas como las que se advierten en la población; así, Murcia, que alcanza la mayor superficie media ( $251 \mathrm{Km}^{2} /$ municipio), supera en 4'04 veces la nacional ( $62 \mathrm{Km}^{2} /$ municipio), y en el extremo opuesto La Rioja o País Vasco (29 $\mathrm{Km}^{2} /$ municipio en ambos casos) presentan una superficie media 2'13 veces más baja que la nacional. 
TABLA A

Tamaño de los municipios españoles

\begin{tabular}{|l|c|c|c|c|}
\hline \multicolumn{1}{|c|}{$\begin{array}{c}\text { Comunidad } \\
\text { autónoma }\end{array}$} & Población total & $\begin{array}{c}\text { Número de } \\
\text { municipios }\end{array}$ & $\begin{array}{c}\text { Población } \\
\text { media }\end{array}$ & $\begin{array}{c}\text { Superficie } \\
\text { media }\end{array}$ \\
\hline Madrid & 6.386 .952 & 179 & 35.681 & 45 \\
\hline Murcia & 1.446 .520 & 45 & 32.144 & 251 \\
\hline Canarias & 2.118 .519 & 88 & 24.074 & 84 \\
\hline Baleares & 1.095 .476 & 67 & 16.349 & 74 \\
\hline Asturias & 1.084 .109 & 78 & 14.650 & 136 \\
\hline Andalucía & 8.353 .843 & 771 & 10.835 & 113 \\
\hline Valencia & 5.094 .675 & 541 & 9.417 & 43 \\
\hline Galicia & 2.796 .089 & 315 & 8.876 & 94 \\
\hline País Vasco & 2.172 .175 & 250 & 8.688 & 29 \\
\hline Cataluña & 7.475 .420 & 946 & 7.902 & 34 \\
\hline Cantabria & 592.250 & 102 & 5.806 & 52 \\
\hline ESPAÑA & 46.745 .807 & 8.108 & 5.765 & 62 \\
\hline Extremadura & 1.102 .410 & 383 & 2.878 & 108 \\
\hline Navarra & 630.578 & 272 & 2.318 & 38 \\
\hline Castilla-La Mancha & 2.081 .313 & 919 & 2.264 & 86 \\
\hline La Rioja & 321.702 & 174 & 1.848 & 29 \\
\hline Aragón & 1.345 .473 & 731 & 1.840 & 65 \\
\hline Castilla y León & 2.553 .301 & 2.248 & 1.135 & 83 \\
\hline & & & & \\
\hline
\end{tabular}

Fuente: elaboración propia con datos del INE de 2010.

En el gráfico 1 pueden apreciarse las diferencias entre Comunidades Autónomas en la población media/municipio. Los datos invitan a distinguir, según queda reflejado en el gráfico 2, por un lado, el conjunto formado por la Comunidad de Madrid y las Comunidades marítimas, que se sitúan por encima de la media estatal con una población de 11.450 habitantes/municipio, y, por otro lado, las Comunidades del interior peninsular con 1.700 habitantes/municipio. 
GRÁFICO 1

Población media/municipio en CC.AA.

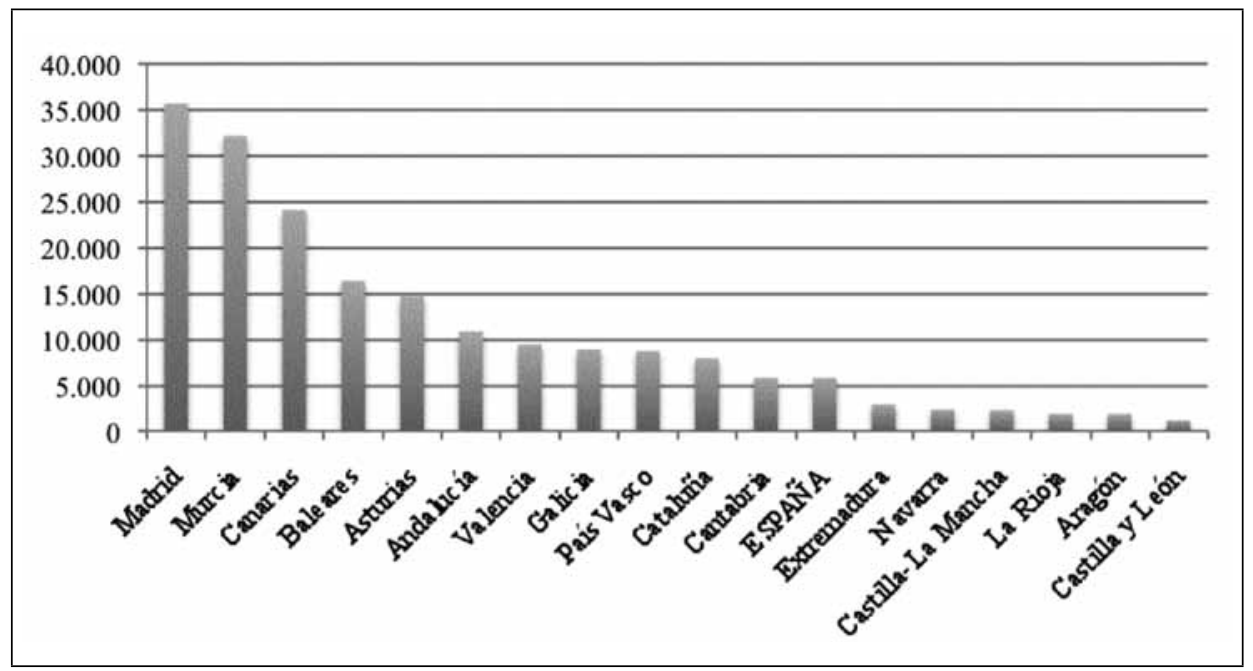

Fuente: elaboración propia.

\section{GRÁFICO 2}

Población media municipal por bloques de CC.AA.

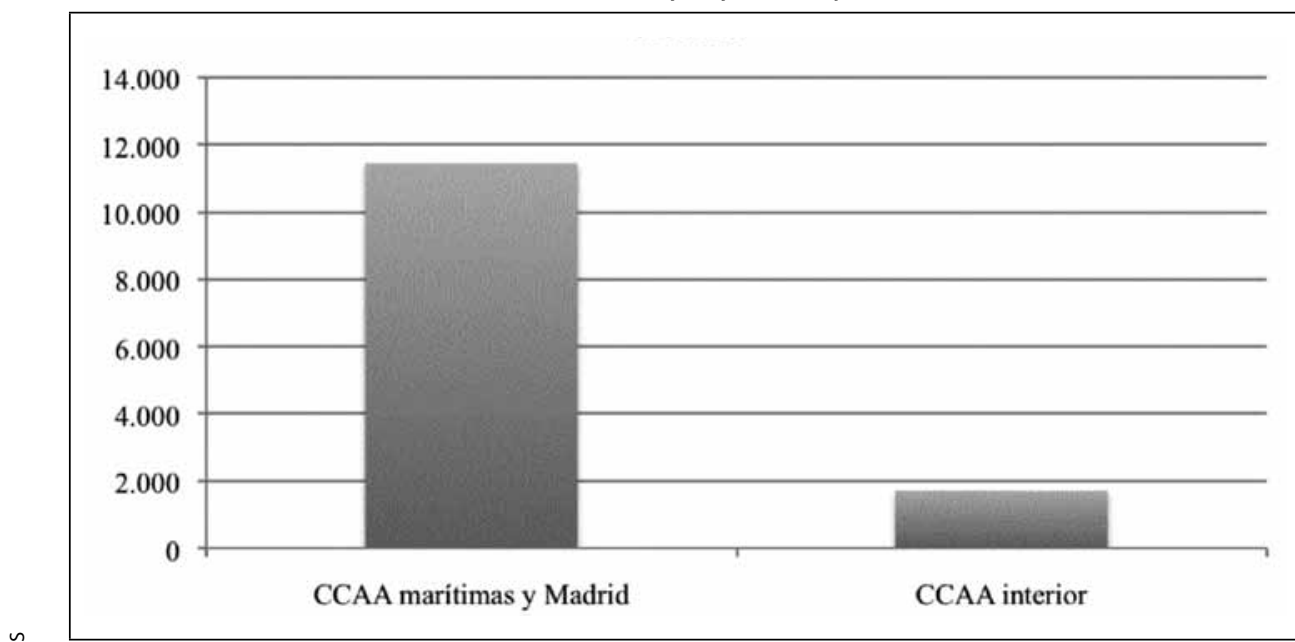

Fuente: elaboración propia.

Estamos pues ante una problemática que se plantea de manera diversa en función de los territorios considerados, lo que propicia su consideración como una cuestión interna de cada Comunidad Autónoma, máxime cuando son tantos los elemen70 tos adicionales que pueden determinar sensibles variantes en la imagen de los mapas 
municipales autonómicos. Bastaría, por ejemplo, con excluir de los respectivos cómputos las áreas metropolitanas de Madrid (4.567.190 habitantes en el ámbito de la antigua COPLACO) o Barcelona (3.511.729 habitantes en el ámbito de la EMM) para que la población media de los restantes municipios madrileños bajara de 35.681 a 11.665 habitantes/municipio o la de los catalanes se colocara sensiblemente por debajo de la media estatal pasando de 7.902 a 4.271 habitantes/municipio.

El mapa municipal de la España interior ofrece el aspecto desolador propio de un contexto rural dominado por la alta despoblación y el fuerte envejecimiento. En el conjunto de las dos Castillas, Extremadura, La Rioja, Navarra y Aragón, la población media se sitúa en 1.700 habitantes/municipio, dato que empeora conforme reducimos la escala. Así, en Aragón, se bajaría a 953 habitantes/municipio si excluyéramos del cómputo a la capital Zaragoza, constatándose que sólo 21 de los 731 municipios aragoneses superan los 5.000 habitantes (el 2'87\%), 522 son de menos de 500 habitantes (71'4\%) y 153 no llegan a los 100 habitantes (20'9\%).

La comparación con los restantes Estados miembros de la Unión Europea no resulta sencilla debido a la disparidad de cifras que ofrecen las fuentes disponibles: la fuente estadística de la Unión Europea, Eurostat, suma en el año 2010 un total de 121.601 unidades del más bajo nivel (LAU 2), pero entre ellas no se incluyen los municipios de gran tamaño de algunos Estados y, en cambio, figuran niveles de tipo parroquial no equiparables a municipios en otros Estados; Dexia Reasearch Department (2008) computa 91.252 municipios y M. Izu Belloso (2007) contabiliza 112.119 municipios. Mis modestos cálculos elaborados a partir de los datos de Wikipedia del año 2010 me dan la cifra de 86.938 municipios, que situarían a España ( 5.765 habitantes y $62 \mathrm{Km}^{2} /$ municipio) a escasa distancia de la media de la Unión Europea (5.804 habitantes y 51'6 Km²/municipio). No obstante, la diferencia sería más notable simplemente marginando el insólito caso de Francia, cuyos 36.571 municipios suponen el 42'5\% del total de los 86.309 municipios de los 27 Estados de la Unión Europea, de manera que, sin la aportación francesa, la media europea se situaría en 8.708 habitantes y 74 '9 Km²/municipio.

En todo caso, los mapas municipales de los Estados de la Unión Europea presentan una amplia diversidad, según puede apreciarse en la tabla B, debido a las variadas trayectorias históricas y también, aunque en menor medida, a los condicionantes geográficos, sociales o económicos. La organización del territorio se manifiesta, ante todo, como un producto esencialmente determinado por la voluntad política en determinados períodos históricos, aunque, en verdad, algunas opciones son adecuadas para calar con mayor facilidad en la población resultando por ello su alteración más difícil. En este sentido, la experiencia demuestra que la aplicación del dogma revolucionario de origen francés que llevó a constituir como municipios a todos los pueblos (en realidad, a todas las parroquias) ha determinado mapas municipales de muy complicada modificación, por ejemplo, en Francia, Italia y España. En cambio, la formación de municipios integrados por varios núcleos de población facilita las sucesivas reformas de los mapas municipales como se advierte en las experiencias de Suecia, Reino Unido o Dinamarca. 
TABLA B

Tamaño de los municipios en la Unión Europea

\begin{tabular}{|c|c|c|c|c|}
\hline Estado & Población total & $\begin{array}{l}\text { Número de } \\
\text { municipios }\end{array}$ & Población media & $\begin{array}{l}\text { Superficie } \\
\text { media }\end{array}$ \\
\hline Eslovaquia & 5.425 .000 & 39 & 139.102 & $1.252^{\prime} 43$ \\
\hline Reino Unido & 61.284 .806 & 468 & 130.950 & $523^{\prime} 11$ \\
\hline Dinamarca & 5.535 .000 & 98 & 56.479 & 439'77 \\
\hline Lituania & 3.281 .400 & 60 & 54.690 & $1088^{\prime} 38$ \\
\hline Irlanda & 4.470 .700 & 92 & 48.594 & $465 ’ 38$ \\
\hline Países Bajos & 16.785 .088 & 443 & 37.889 & $65^{\prime} 60$ \\
\hline Portugal & 11.317 .192 & 308 & 36.744 & 299'97 \\
\hline Suecia & 9.299 .000 & 290 & 32.065 & $1.551^{\prime} 60$ \\
\hline Bulgaria & 7.449 .000 & 278 & 26.794 & $399 ' 25$ \\
\hline Chipre & 784.301 & 33 & 23.766 & 280 '30 \\
\hline Letonia & 2.231 .000 & 118 & 18.906 & $547 ’ 36$ \\
\hline Bélgica & 10.827 .000 & 589 & 18.382 & 51'37 \\
\hline Polonia & 38.453 .000 & 2.489 & 15.449 & $125^{\prime} 62$ \\
\hline Finlandia & $5 \cdot 326.314$ & 431 & 12.358 & 781'97 \\
\hline Grecia & 11.260 .401 & 1.033 & 10.900 & $127^{\prime} 68$ \\
\hline Eslovenia & 2.047 .000 & 210 & 9.747 & $96^{\prime} 44$ \\
\hline Italia & 60.545 .940 & 8.094 & 7.480 & $37^{\prime} 22$ \\
\hline Rumania & 21.932 .000 & 2.951 & 7.432 & $80 ' 78$ \\
\hline Alemania & 82.604 .000 & 12.379 & 6.673 & 31'07 \\
\hline Malta & 413.609 & 68 & 6.082 & $4^{\prime} 64$ \\
\hline U. EUROPEA & 504.636 .783 & 86.938 & 5.804 & $51^{\prime} 60$ \\
\hline España & 46.745 .807 & 8.108 & 5.765 & $62 ' 17$ \\
\hline Estonia & 1.287 .000 & 227 & 5.669 & 199'23 \\
\hline Luxemburgo & 502.000 & 118 & 4.254 & 21'91 \\
\hline Austria & 8.334 .325 & 2.358 & 3.534 & $35 ' 56$ \\
\hline Hungría & 9.982 .000 & 3.152 & 3.167 & $29 ' 51$ \\
\hline Francia & $66.007 \cdot 374$ & 36.571 & 1.805 & $18^{\prime} 46$ \\
\hline R. Checa & 10.506 .813 & 6.249 & 1.681 & $46 ' 91$ \\
\hline
\end{tabular}

72 Fuente: elaboración propia con datos de Wikipedia de 2010. 


\section{LA IMPORTANCIA DEL TAMAÑO DE LOS MUNICIPIOS}

¿Pero importa el tamaño? Algo sí. No es una cuestión que pueda responderse con alcance general en términos precisos estableciendo una talla municipal mínima, pero sin duda en cada experiencia han de respetarse umbrales cuya inobservancia determina la falta de operatividad del municipio. En función de los valores propios de la ciudad-estado, indicaba Aristóteles que "la justa proporción para el cuerpo político consiste, evidentemente, en que tenga el mayor número posible de ciudadanos que sean capaces de satisfacer las necesidades de su existencia; pero no tan numerosos que puedan sustraerse a una fácil inspección o vigilancia" (La Política, libro IV, cap. IV).

En la moderna ciencia política, desde la obra de R.A. Dahl y E.R. Tufte (1973) la relación entre tamaño y democracia se plantea como un problema de equilibrio entre los principios de capacidad (o eficacia) y proximidad (o participación). En consecuencia, ha de considerarse, de una parte, la "capacidad productiva" de los entes públicos, esto es, su aptitud para responder plenamente a las necesidades y preferencias colectivas, y de otra parte, la "proximidad" a los ciudadanos a fin de permitir el control democrático. La falta de equilibrio entre ambos valores caracteriza a las organizaciones públicas inadecuadas, pues, como indicaba el propio Dahl (1971: 960) con directa referencia a las ciudades, "la participación en ámbitos verdaderamente grandes llega a ser mínima y en ámbitos verdaderamente pequeños llega a ser trivial”.

La aplicación de los anteriores planteamientos al ámbito municipal suele generar posiciones enfrentadas. Los partidarios de las fusiones municipales se quejan de que los pequeños municipios no pueden atender las modernas demandas de servicios públicos; y al contrario, quienes se oponen a las fusiones estiman que la democracia local experimenta reducciones crecientes conforme va ensanchándose la talla del municipio. En realidad nos encontramos frecuentemente ante debates sobre creencias que en bastantes ocasiones se desarrollan con argumentos arbitrarios. Así, en un extremo, podemos encontrarnos con acaloradas defensas de la eficacia y del ahorro de costes que derivarían necesariamente de la formación de grandes municipios, mientras que en el lado opuesto se ensayan versiones más o menos actualizadas del clásico "menosprecio de corte y alabanza de aldea".

Los estudios empíricos ofrecen respuestas mucho más matizadas. En relación con los importantes y sucesivos procesos de reforma del mapa municipal en Dinamarca, el análisis de datos agregados llevado a cabo por C. Albrekt Larsen (2002: 330-331) explica que, si bien la participación directa de los ciudadanos es más intensa en los pequeños municipios, la confianza en los políticos se incrementa en los grandes municipios, que proporcionan también mayores posibilidades de resistencia y movilización cuando prevalecen sentimientos de hostilidad frente a los representantes; además, las encuestas desarrolladas demuestran también que el tamaño del municipio carece de influencia en el grado de interés o conocimiento de las políticas locales. A parecidas conclusiones llega el estudio de A. Ladner (2002: 826-827) sobre la práctica de las diversas modalidades de democracia directa en Suiza, cuya relación con el ta- 
maño del municipio no resulta tan evidente como a primera vista pudiera parecer, pues si la participación en concejos abiertos ciertamente sólo es posible en los pequeños municipios, en contraste, las iniciativas ciudadanas y el empleo del referéndum tienen mayor importancia en los municipios grandes. Finalmente el trabajo sobre Hungría, Polonia y Rumania de D. Pop (2005: 197-199) permite sostener la mayor capacidad de los municipios grandes para asegurar la participación efectiva de los ciudadanos aun en contextos generales de limitada democracia local. No obstante, conviene no dejar deslumbrarse por los planteamientos estadísticos cuando tratamos de problemas sociales; en tal sentido, como subraya K. Houlberg (2010: 310), cabe encontrar estudios científicos para todos los gustos en relación con el tamaño óptimo de los municipios.

La cuestión resulta condicionada tanto por fuerzas inmovilistas que pretenden mantener el statu quo, como por movimientos que propugnan la modernización administrativa continua. Entre esos dos polos de tensión se pueden identificar elementos razonables que conviene rescatar de los planteamientos extremistas:

a) En el primer sentido, no puede olvidarse la alta relación que los mapas municipales históricos pueden presentar respecto a los sentimientos de arraigo de la población. Ciertamente, el fenómeno no se presenta de manera idéntica en todas las experiencias, como cabe comprobar en relación con las reformas territoriales llevadas a cabo en países de influencia soviética (M. Illner, 2003: 117-118). Pero, aun así, las señas de identidad vinculadas a las entidades locales juegan un papel que no cabe desconocer, al menos, hasta el nivel en el que los legítimos lazos de pertenencia pueden llegar a transformarse en insolidaridad social o son objeto de manipulación dentro de las relaciones de dominación política o económica; extremos sobre los que parece útil reproducir la constatación de M.E. Warren (2001: 77-78):

"A medida que las unidades de gobierno se hacen más pequeñas y más locales, se hacen más vulnerables a los límites impuestos por aquellos que controlan las industrias locales o regionales, con el efecto irónico de que, cuando disminuyen las limitaciones impuestas por el tamaño y por la escala, aumentan los límites impuestos por la vulnerabilidad económica."

En toda actuación sobre los mapas municipales, resulta clave la actitud de los líderes locales, que si condensan las aspiraciones y frustraciones de la población, también pueden potenciarlas o contenerlas. De esta manera, el poder organizado de los alcaldes en la Association des Maires de France ha influido notablemente en la consolidación de los miles de municipios galos que subsisten desde que fueron reconocidos en 1789 (R. Hertzog, 2010: 291); en cambio, en Grecia los líderes locales no generaron una fuerte oposición general a las importantes reformas del Plan Kapodistrias de 1997 bajo la influencia de nuevas tendencias económicas y demandas sociales ( $\mathrm{N}$. Hlepas, 2010: 45-48).

b) En relación con las tendencias modernizadoras, ha de aceptarse la necesi74 dad de configurar entidades municipales que no sólo sean viables, sino que permitan 
también promover activamente el desarrollo cultural, social y económico de las poblaciones. El objetivo no puede ciertamente limitarse a la mera subsistencia, al mantenimiento vegetativo de simulacros de entes públicos. Por otra parte, en la atribución de responsabilidades habrá que tener en cuenta, como señala H. Hermenier (2008: p. 6), que los ámbitos adecuados varían en función de las tareas públicas implicadas, que determinan diferentes exigencias en las correspondientes escalas de la organización pública.

Ahora bien, lo que no resulta fácilmente admisible es aceptar un principio de cambio permanente de las estructuras territoriales, como parece propugnar algún autor siguiendo planteamientos de la Teoría del Caos, la Nueva Gestión Pública o la Gobernanza (G. Márquez Cruz, 2010: 137-145). La organización pública requiere de una cierta estabilidad, al menos en los niveles territoriales básicos, pues, en cambio, el ejercicio de las responsabilidades atribuidas a las Administraciones territoriales admite la adopción de soluciones organizativas internas flexibles.

Si de los planteamientos generales y comparados pasamos ahora a la reflexión sobre el mapa municipal español, ha de constatarse que contamos con centenares de municipios incapaces de su misma subsistencia: 981 municipios de menos de 100 habitantes (12'09\% del total) y 6.948 municipios de menos de 5.000 habitantes ( 85 '7\% del total). Los umbrales mínimos que han de respetar los entes públicos no son respetados.

En directa referencia a los pequeños municipios navarros, pero que fácilmente podría ser aplicada a otras Comunidades Autónomas y cabría conectar con el cuadro de oligarquía y caciquismo que a principios del siglo XX nos ofreció Joaquín Costa, la dramática situación está perfectamente descrita por un autor con amplia experiencia en el mundo local (M. Izu Belloso, 1999):

“La supervivencia del pequeño municipio provoca su permanente minoría de edad. Su insuficiencia de capacidad económica y técnica para ejercer la mayoría de las teóricas competencias municipales origina la persistencia de la tutela de una Administración superior, en nuestro caso la foral. Aunque la ley ha eliminado de iure la tutela que el antiguo Reglamento para la Administración Municipal de Navarra atribuía a la Diputación, de facto esa tutela se mantiene a través de los más variados mecanismos: planes de infraestructuras locales, planes directores, proyectos sectoriales de incidencia supramunicipal (qué fácil, con nuestro minifundismo municipal, que cualquier proyecto lo sea), fondo de participación en los impuestos de $\mathrm{Na}$ varra, etc. Ya que los municipios ni saben ni pueden, es la Administración Foral la que planifica, regula, decide $y$, sobre todo, la que administra el dinero. El papel de los alcaldes sigue siendo recorrer despachos para que su municipio sea afortunado con su inclusión en los planes, proyectos, programas, subvenciones. Antes los alcaldes hacían antesala ante el despacho del diputado de su merindad; ahora se pierden en un laberinto de departamentos, servicios, responsables políticos y funcionarios. ¿Y qué sucede cuando el Ayuntamiento sí tiene capacidad? Son pocos, pero los hay. Lo siento, la norma se ha hecho para todos igual; pase usted con sus ciento 
ochenta mil o sus veinte mil habitantes por el aro previsto para los municipios de cincuenta vecinos, usted también es menor de edad. Presente su instancia en el Registro General del Gobierno de Navarra; pida autorización, pida subvención, adjunte su proyecto, no olvide la memoria anual y la evaluación de resultados. Igual que esos padres que no quieren reconocer que sus hijos ya se han hecho mayores, a la Administración Foral no le gusta la idea de que algún día los municipios sometidos a su tutela crezcan. El papel tutelar -cuasipaterno, cuasimaterno- del Gobierno de Navarra es políticamente demasiado provechoso para renunciar a él; el día que sean los municipios los que decidan no serán los consejeros quienes partan y repartan y rentabilicen políticamente cada peseta que se gasta y cada inauguración que se celebra."

Por otra parte, conviene no olvidar, como destaca D. Loperena (1988: 115) que el municipio, además de constituir un ámbito administrativo, es también un espacio de participación política cuyo desenvolvimiento exige un cuerpo electoral de un cierto tamaño. Como dice el autor "no existen comunidades de esa naturaleza en pequeños contingentes humanos constituidos por la suma de unas cuantas familias, en las cuales las relaciones interpersonales e intercolectivas están al margen de cualquier razonable examen político, impulsadas por los lazos de sangre, las amistades, enemistades y otros condicionantes". Cabría incluso añadir que difícilmente pueden existir Administraciones públicas que puedan ejercer con objetividad sus potestades (tributaria, expropiatoria, sancionadora, etc.) en ámbitos tan reducidos.

Si se quiere contar con una narración oficial, cabe reproducir párrafos de la comunicación del Gobierno de Aragón a las Cortes de Aragón con el título "Hacia una política demográfica en Aragón" (BOCA, 239, 3 febrero 1999, pp. 10595 ss.). Allí se describe que, "como consecuencia de su actual estructura demográfica excesivamente envejecida”, unos 500 municipios (más del 69\% de los 731 existentes en la Comunidad Autónoma) "han perdido ya su capacidad endógena de crecimiento natural y han entrado en un proceso de declive y agotamiento poblacional"; no se espera ningún nacimiento en esos municipios, dado que ya no existen en ellos personas en edad fértil. Y continúa la comunicación:

"Entre los efectos socioeconómicos de la despoblación de grandes áreas y de la dispersión de los habitantes en municipios pequeños y muy pequeños está la dificultad de abastecer de servicios adecuados a toda la población. Así, por ejemplo, las carencias en las infraestructuras viarias porque, por la extensión territorial y dispersión de la población, sería precisa una red de carreteras muy densa, con cuantiosas inversiones en construcción, y, sobre todo, en mantenimiento, con escasos usuarios finales."

A continuación, vamos a exponer las características y el alcance de las distintas vías de actuación diseñadas para hacer frente a la situación de excesiva fragmentación de los mapas municipales: a) cooperación intermunicipal, b) fusiones de munici76 pios, y c) comarcalización. 


\section{LA COOPERACIÓN INTERMUNICIPAL, SOLUCIÓN FRANCESA}

El origen del problema del minifundismo municipal viene identificándose en el modelo revolucionario francés implantado por la Ley de 14 diciembre 1789, cuya aplicación generó una organización territorial con predominio de los pequeños municipios. Quizás merece la pena recordar que en la Asamblea Nacional se presentaron dos modelos: el de Thouret, Sièyes y Condorcet, que proponían constituir unas 6.500 municipalidades con fuertes exigencias de población y superficie al considerar que la democracia resulta fortalecida en los grandes municipios, y el de Mirabeau, que pretendía mantener estructuras débiles en el territorio a fin de controlar la preponderancia de las ciudades. Finalmente se estableció este último sistema conforme a la máxima "habrá un municipio en cada ciudad, pueblo, parroquia o comunidad rural”, lo que llevó a constituir inicialmente unos 44.000 municipios.

Poco después, en la Constitución de 1795 se estableció la figura de los municipios cantonales compuestos por varios núcleos de población. Sin embargo, la ejecución del modelo generó amplios debates zanjados por la decisión napoleónica de restaurar el mapa municipal revolucionario. Las unidades locales fueron paulatinamente consolidando su autonomía, desarrollando competencias y generando también ámbitos de influencia política a través de los alcaldes, al permitirse la acumulación de mandatos representativos locales y nacionales.

Realmente el problema deriva de haber otorgado a todos los municipios el régimen de Administraciones públicas, pues como subraya A. Nieto (2008: 280-281) "siempre han existido innumerables municipios, pero ni la teoría constitucionalista ni la administrativista les equiparaban o denominaban administraciones públicas por la sencilla razón de que no lo eran"; la confusión empieza cuando se les termina reconociendo, por una "maniobra técnico-jurídica", la misma personalidad jurídica que a la Administración del Estado.

Las notables carencias de los pequeños municipios han terminado por encontrar una pragmática solución en la cooperación intermunicipal como ha expuesto R. Hertzog (2010: 286). Desde 1890 se permiten en Francia las asociaciones voluntarias de municipios dotadas de personalidad jurídica para ejercer funciones públicas comunales. El empleo de tales uniones se desarrolló particularmente en relación con materias de tipo técnico como el abastecimiento de agua, la recogida de residuos y el suministro de energía eléctrica o gas.

No obstante, hubo también intentos de llevar a cabo la reforma del mapa municipal mediante fusiones voluntarias. Una primera experiencia en tal sentido tuvo lugar en el período 1930-1957 tras grandes debates nacionales sobre la vinculación de la reforma municipal a la reducción del gasto público y al logro de una mayor eficiencia en la gestión pública. Los programas de fusiones se sucedieron incluso durante la Segunda Guerra Mundial en la Francia sometida al general Pétain. Sin embargo, el 
fracaso acompañó a estas políticas, como demuestra el dato de que únicamente se registraran 350 fusiones que afectaron a 756 municipios, tratándose casi siempre de uniones de dos pequeñas poblaciones que escasamente implicaban una mejora de la situación general.

La intermunicipalidad se planteó formalmente en 1959 por el presidente De Gaulle como la solución de los problemas de los pequeños municipios. Pese a tratarse de un instrumento de uso voluntario, los prefectos han sabido manejar hábilmente los hilos de la negociación política, el asesoramiento legal, el soporte técnico y los incentivos económicos para conseguir el empleo de las fórmulas asociativas entre municipios. En línea con experiencias anteriores ya mencionadas, particular importancia han seguido teniendo las asociaciones intermunicipales constituidas para la construcción de redes que precisan inversiones a largo plazo, escala adecuada para su desenvolvimiento y especial asesoramiento técnico, como las relativas al abastecimiento de agua, los transportes, la recogida de basuras o las vías de comunicación.

Sin embargo, en 1971 se planteó de nuevo una drástica reducción del número de municipios dentro de un amplio programa de reformas del régimen local. Los resultados consistieron en pasar de 38.600 a 36.600 municipios (que son aproximadamente los actualmente existentes), lo que fue considerado un fracaso rotundo. Su impacto político fue tan grande que llevó a consolidar la idea de que las fusiones municipales son imposibles en Francia debido a la oposición de una gran mayoría de políticos y ciudadanos.

La compleja legislación relativa a la cooperación intermunicipal fue objeto de medidas simplificadoras en 1999. Así, se previeron tres grandes tipos de asociaciones intermunicipales: a) las comunidades de municipios, que organizan la cooperación general entre municipios rurales y pequeñas ciudades, y son un total de 2.406 incluyendo a 27'5 millones de personas; b) las comunidades de aglomeración apropiadas para entornos de ciudades medianas, pues deben comprender un mínimo de 50.000 personas incluyendo al menos una ciudad de 15.000 habitantes, comunidades de las que existe un número de 179 afectando a 21'3 millones de personas; y c) las comunidades urbanas previstas para ciudades metropolitanas de más de 500.000 personas, que pueden llegar a recibir los poderes de los departamentos según una reforma de 2009, y de las que hay 16 con un total de 7'3 millones de personas.

En el gráfico 3 se recogen los promedios de habitantes implicados en cada uno de esos grandes tipos de comunidades intermunicipales: 11.430 en las comunidades de municipios, 118.994 en las comunidades de aglomeración y 456.250 en las comunidades urbanas. Realmente estamos ante una alternativa a la organización municipal tradicional con un conjunto de 260 comunidades que afectan a una población media de 21.568 habitantes/comunidad, a gran distancia de los 1.805 habitantes/municipio como cabe contemplar en el gráfico 4 . 


\section{GRÁFICO 3}

Francia, población media/tipo de comunidad intermunicipal

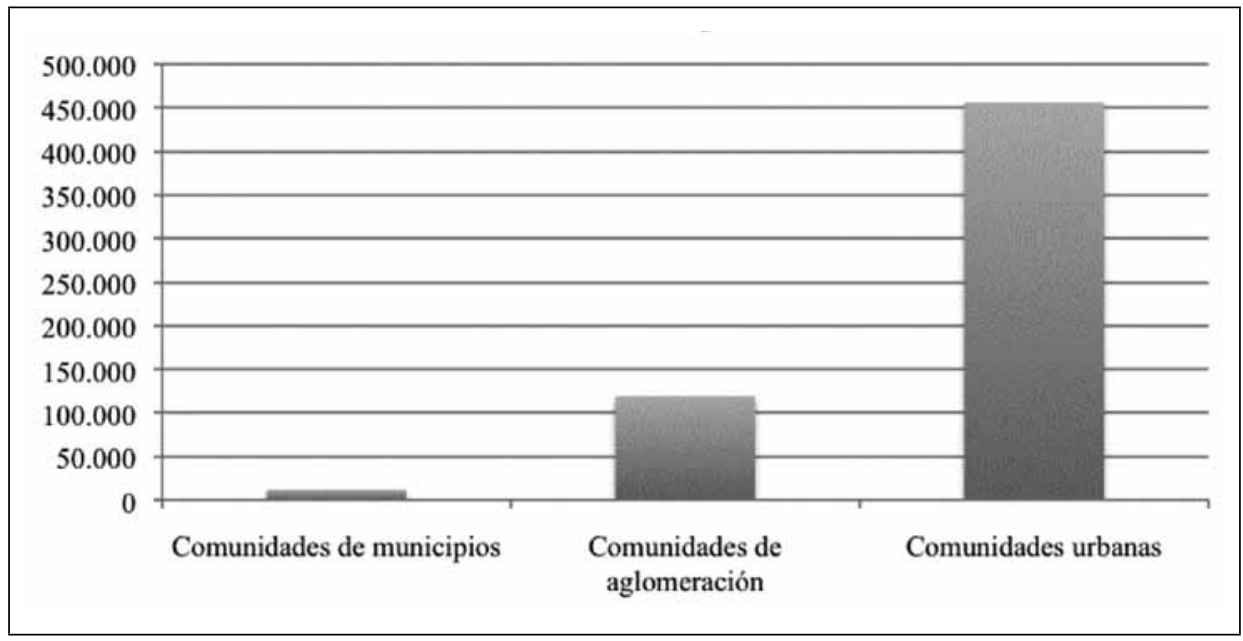

Fuente: elaboración propia.

\section{GRÁFICO 4}

Francia, población media de municipios y comunidades

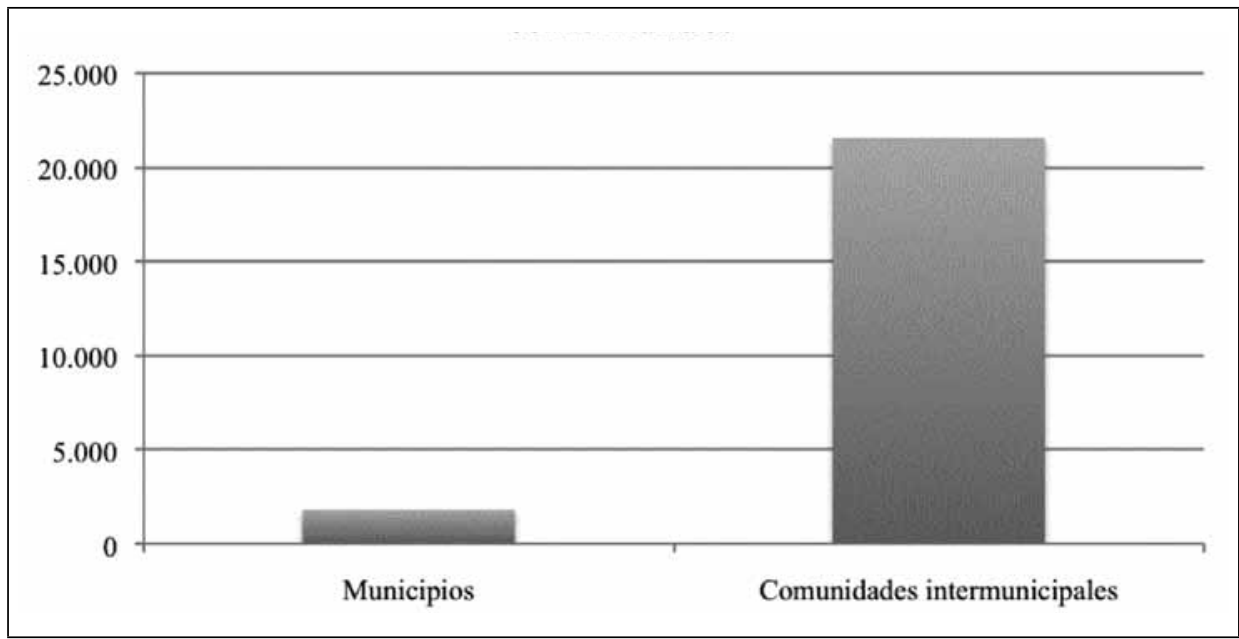

Fuente: elaboración propia.

La intermunicipalidad a la francesa constituye sin duda un gran éxito de la política de organización territorial a largo plazo seguida por Gobiernos de izquierda y de derecha. Los partidos políticos, el cuerpo de prefectos y las autoridades locales (tan mezcladas con las nacionales) pueden considerarse los protagonistas del consenso 
logrado en la materia. Se trata de un modelo que cabe considerar asentado, pues las comunidades proporcionan los servicios públicos básicos, se ha creado un clima de solidaridad y confianza entre la clase política local y la burocracia estatal, y los ciudadanos parecen altamente satisfechos.

No obstante, el sistema manifiesta también un elevado grado de complejidad, puesto que cada comunidad tiene su propia configuración y sus propias funciones. Se advierten también ciertas confusiones en la percepción de las responsabilidades públicas, y una tendencia al crecimiento constante del gasto debido a la dependencia financiera de transferencias estatales. Finalmente, la inestabilidad parece natural al sistema, pues la posibilidad de abandono de los municipios por discrepancias o enfrentamientos partidistas siempre está presente. De ahí que, en el futuro, la experiencia de las comunidades, al haber hecho decaer los patriotismos locales, pudiera ser aprovechada para generar un eventual proceso de fusiones de municipios.

\section{LAS FUSIONES DE MUNICIPIOS}

Las fusiones de municipios constituyen el remedio más directo de los problemas de la excesiva fragmentación del mapa municipal, siempre y cuando respondan a una actuación sistemática y, en alguna medida, obligatoria. De las fusiones voluntarias consistentes en la incorporación de un municipio a otro o en la formación de un nuevo municipio por unión de varios, poco cabe esperar en un plano general, pues se trata de operaciones aisladas que no solucionan el problema de la adecuada organización del territorio.

Podría ciertamente diseñarse un política de estímulo de las fusiones voluntarias, pero las experiencias demuestran el escaso éxito de tales operaciones. Frecuentemente producen uniones de dos pequeños municipios, que terminan por generar los mismos inconvenientes que anteriormente se presentaban por separado.

Vamos a referirnos, pues, a las operaciones de remodelación directa del mapa municipal llevadas a cabo por el poder público al que corresponde la competencia en la materia. Primero, expondremos los débiles intentos planteados en la experiencia española; luego, nos referiremos a las políticas experimentadas en algunos países europeos.

\section{A) Historia española}

En España, la Constitución de 1812 importó el modelo francés al establecer en el art. 310:

"Se pondrá ayuntamiento en los pueblos que no lo tengan y convenga le haya, no pudiendo dejar de haberle en los que por sí o con su comarca lleguen a 1.000 almas y también se les señalará el término correspondiente." 
El rápido proceso de implantación de los municipios constitucionales, tan apenas contenido con el retorno al Absolutismo (1813-1821), en seguida manifestó sus carencias determinando el inicio de una serie de estériles intentos legislativos de limitar el número de municipios mediante la exigencia de una determinada población ( $\mathrm{F}$. Sosa y P. De Miguel, 1987: 15-53). En el gráfico 5 se han representado las cifras de población mínima establecidas para mantener los municipios existentes en diferentes normas y proyectos de ley a lo largo de los siglos XIX y XX.

\section{GRÁFICO 5}

Población exigida para mantener municipios en la legislación histórica del Estado

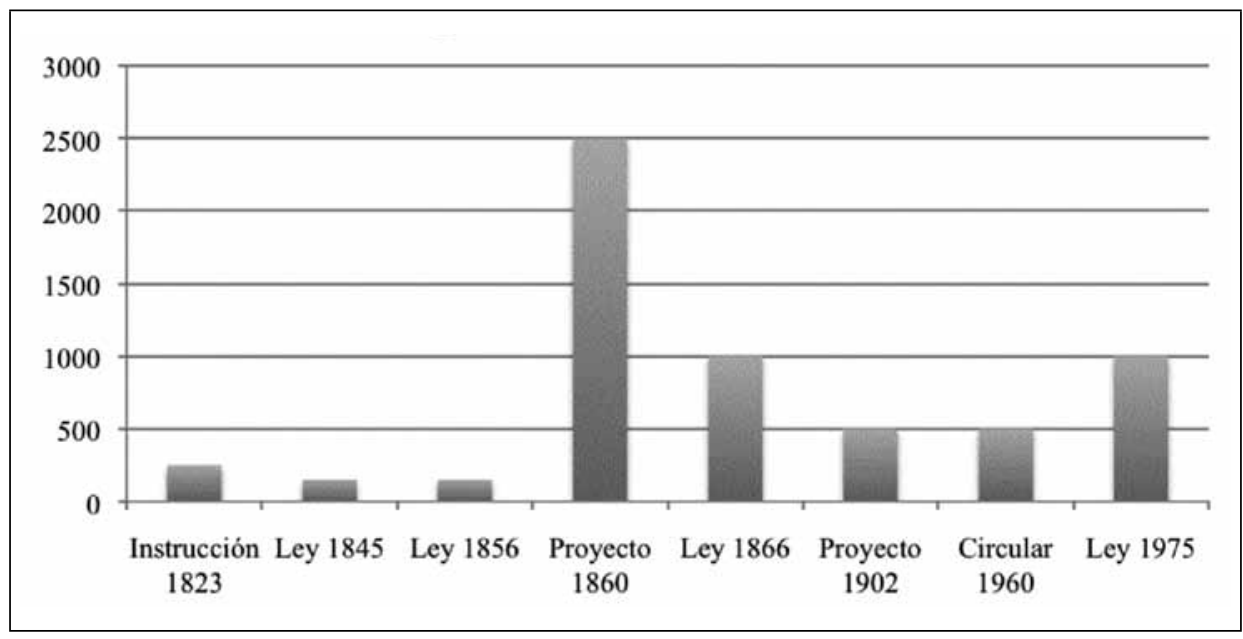

Fuente: elaboración propia.

Ya durante el Trienio Liberal, en la Instrucción para el gobierno económico-político de las provincias de 3 febrero 1823, se previó la supresión de ayuntamientos "por la cortedad del vecindario" (art. 85), supuesto que concurría cuando no tuvieran 50 vecinos (equivalentes a 250 habitantes). La inmediata reinstauración del régimen absolutista (1823-1833) determinaría la supresión de todos los municipios constitucionales, que volvieron, sin embargo, a reestablecerse con ímpetu tras la muerte de Fernando VII, sin que en el RD de 23 julio 1835 para el arreglo provisional de los ayuntamientos del Reino se obligara a contener el proceso, pues únicamente se previó que la formación de nuevos ayuntamientos sólo sería posible en los núcleos compuestos de más de 100 vecinos (500 habitantes), pero sin hacer referencia alguna a los municipios ya existentes. Habrá que esperar a las Leyes de Ayuntamientos de 1845 y 1856 para que, además de mantenerse la anterior cifra en relación con los nuevos municipios, fuera reimplantada la exigencia de una población mínima en los municipios existentes, siquiera fuera con una notable rebaja, pues pasó a 30 vecinos (150 habitantes).

Las ideas contrarias al mantenimiento de los pequeños municipios encontraron un buen exponente en el proyecto de Ley Municipal de Posada Herrera de 1860, que 
planteaba suprimir los ayuntamientos de menos de 500 vecinos (2.500 habitantes). En la exposición de motivos se alegaban los "graves inconvenientes que ofrecen esas municipalidades microscópicas", que "pueden considerarse familias dilatadas" y que quedan "sometidas ciegamente a la influencia del vecino más rico o más astuto o menos ignorante", siendo "no sólo una rémora constante para la Administración en general, sino incapaces de llenar el objeto propio de una asociación de su índole”. De conformidad con tales planteamientos, el RD de 21 octubre 1866 firmado por González Bravo dispuso la supresión de los municipios de menos de 200 vecinos (1.000 habitantes), formándose proyectos de reforma del mapa municipal en cada provincia, cuya continuidad en este aspecto, tras la Revolución de 1868, fue asegurada por el Decreto de 21 octubre 1868, que firmaba Sagasta, también opuesto al mantenimiento de los municipios de menos de 1.000 habitantes. Sin embargo, en la Ley Municipal de 1870 las exigencias de una población mínima se referían no a los municipios existentes, sino exclusivamente a la creación de nuevos municipios, que requerían de 2.000 habitantes.

Termina así prácticamente la etapa decimonónica de intentos de reformar el mapa municipal, pues en lo sucesivo el legislador parece haber aceptado, al menos por largo tiempo, que la supresión de las municipalidades de escaso vecindario es "remedio que choca con el invencible sentimiento de la conservación de estas modestas agrupaciones", tal y como se expresaba en el proyecto de Ley Municipal de Romero Robledo de 1884. Sólo en 1902, en el proyecto de Moret, que conectaba con las propuestas de reforma realizadas por las Diputaciones Provinciales conforme a la RO de 31 mayo 1901, se llegó a proponer la incorporación de los municipios de menos de 500 habitantes a los ayuntamientos más próximos, pretendiéndose también que el Gobierno diera "cuantas facilidades y ventajas permitan las leyes" para que los municipios de menos de 2.000 habitantes se agruparan en un ayuntamiento común.

El saldo final de las fusiones decimonónicas parece de muy escasa entidad. Con los datos que nos proporciona el Nomenclátor municipal a partir de 1857, sabemos que desde ese año hasta 1960 el número de municipios españoles bajó tan solo de 9.315 a 9.202 .

Desde luego, la implantación de las corrientes iusnaturalistas en relación con el municipio no favoreció la racionalización del mapa municipal. Así, el Estatuto Municipal de 1924 partió de la idea de que el municipio "no es hijo del legislador; es un hecho social de convivencia, anterior al Estado, y anterior también y, además, superior, a la ley", tal y como se indicaba en su exposición de motivos. La convivencia, como hecho natural impuesto al legislador, "se da en núcleos de gradación ilimitada, desde los insignificantes, que sólo constan de unos cuantos vecinos, hasta los gigantescos que cuentan por millones sus habitantes". En consecuencia, el Estatuto "admite la personalidad municipal allí donde la naturaleza la engendra, sin establecer requisitos de mero artificio", previendo que los acuerdos de fusión, constitución y alteración de términos municipales adoptados por el vecindario y las corporaciones interesadas 82 "serán firmes y se comunicarán al Gobierno civil de la provincia" (art. 21). 
Habrá que esperar a la época franquista para encontrar nuevos intentos de fusión de pequeños municipios (Burgueño, 2004: 11-17). Mediante una circular de la Dirección General de Administración Local de 20 enero 1960 se ordenó a los Gobiernos Civiles elaborar planes de reforma de los términos municipales de las respectivas provincias con la finalidad de suprimir los municipios de población inferior a 500 habitantes y de presupuesto inferior a 100.000.- pesetas. Los proyectos de reforma contenían propuestas ambiciosas que, por ejemplo, en el conjunto de Cataluña, suponían pasar de 1.057 a 598 municipios, si bien solo en escasa medida fueron llevadas a la práctica. Las fusiones voluntarias serían incentivadas mediante la Ley de 23 julio 1966, que se considera la medida de mayor éxito en nuestra historia, pues entre 1960 y 1981 el número de municipios se redujo de 9.202 a 8.022. Finalmente, la Ley de Bases de Régimen Local de 1975 autorizó al Gobierno para imponer las fusiones municipales cuando los municipios afectados no llegaran a 1.000 habitantes, aunque la potestad no fue aplicada.

No obstante, ha de constatarse que los anteriores intentos de reducir el número de municipios resultaban paradójicamente compatibles con el mantenimiento en la legislación de régimen local del régimen tradicional de la segregación de parte de un término municipal para constituir otro municipio independiente. Así, en el art. 15 de Ley de Régimen Local de 1955 la exigencia de que los municipios resultantes de la operación segregadora contaran con recursos suficientes se limitaba al sostenimiento de "los servicios municipales obligatorios". Tan inconsistente exigencia, además, fue asumida en la jurisprudencia con evidentes resabios de la concepción iusnaturalista del municipio, como cabe apreciar en la STS de 15 junio 1984, cuyos planteamientos se prolongan hasta las SSTS de 22 diciembre 1986, 24 y 30 octubre 1989 y 30 enero 1990:

"La natural vocación y aspiración de un grupo humano a constituir un municipio propio por estar arraigado en un determinado territorio y hallarse vinculado entre sí con vigorosos nexos surgidos y mantenidos con ocasión y como consecuencia de comunes y trascendentes circunstancias, es una inclinación que el Derecho, rector por antonomasia y esencia de las relaciones sociales, no puede ignorar ni negar."

En el período democrático, de conformidad con el art. 148.1.2 ${ }^{\text {a }}$ de la Constitución de 1978, la competencia relacionada con las alteraciones de los términos municipales ha pasado a las Comunidades Autónomas por virtud de sus Estatutos de Autonomía. La previsión, como indicamos anteriormente, encaja bien con la diversidad de situaciones que el tamaño de los municipios determina en el territorio español. Aun así, no habría de descartarse la viabilidad de la exigencia estatal de un tamaño mínimo de los municipios con apoyo en la competencia del Estado sobre las bases del régimen jurídico de las Administraciones públicas (art. 149.1.18ª Constitución).

En relación con las competencias autonómicas, algún problema cabría plantear en el caso de Aragón. En efecto, inicialmente el Estatuto de 1982 asumió la competen- 
cia específica sobre "alteraciones de los términos municipales" (art. 35.1.2 ${ }^{\text {a }}$ ), aunque luego, en la llamada reforma amplia del Estatuto llevada a cabo en 1996, la referencia fue sustituida en el mismo precepto por la genérica competencia sobre "régimen local", expresión que, sin duda, incluía la submateria de las alteraciones municipales. Sin embargo, en el nuevo Estatuto de Aragón de 2007 el contenido de la competencia sobre régimen local se define en términos que literalmente parecen exhaustivos, ya que incluyen todas las submaterias que el legislador estatutario considera comprendidas en el régimen local (art. 71.5 del Estatuto de Aragón). Pues bien, sucede que entre tales contenidos no figuran las alteraciones de los términos municipales ni existe ningún enunciado suficientemente genérico que pudiera comprender dicha competencia. Así, en el precepto citado se establece que corresponde a la Comunidad Autónoma "la competencia exclusiva en las siguientes materias", y a continuación leemos:

\begin{abstract}
“En materia de régimen local, la determinación de las competencias de los municipios y demás entes locales en las materias de competencias de la Comunidad Autónoma de Aragón; el régimen de los bienes locales y las modalidades de prestación de los servicios públicos locales, así como las relaciones para la cooperación y colaboración entre los entes locales y entre éstos y la Administración de la Comunidad Autónoma de Aragón.
\end{abstract}

Asimismo, incluye la determinación de los órganos de gobierno de los entes locales, creados por la Comunidad Autónoma y su régimen electoral."

Da la impresión de que, en el intento de seguir las estelas del Estatuto catalán de 2006 y también del andaluz de 2007 procediendo a definir el alcance de las competencias autonómicas, el texto aragonés ha incurrido en un notable olvido. Así, se advierte que en el art. 151.b) del Estatuto de Cataluña, dentro de la enunciación de submaterias "en todo caso" comprendidas en la competencia autonómica, figura "la creación, la supresión y la alteración de los términos tanto de los municipios como de las entidades locales de ámbito territorial inferior". En el art. 59 del Estatuto de Andalucía la misma submateria se incluye dentro las competencias sobre organización territorial y no en las relativas al régimen local recogidas en el art. 60, que parece haber servido de modelo directo al Estatuto de Aragón, pues éste, en su art. 71.5 $5^{\mathrm{a}}$, lleva a cabo una especie de resumen de los enunciados andaluces.

A la vista de lo que parece una omisión, una omisión sorprendente si se tiene en cuenta el notable grado de inframunicipalismo que padece la Comunidad Autónoma de Aragón (ver gráfico 1), quizá no haya más remedio que forzar la literalidad del precepto estatutario aragonés y considerar que la enumeración de las submaterias del régimen local se hace con carácter enunciativo, es decir, bajo la cláusula implícita del "en todo caso incluye", que modula las listas de submaterias contenidas en el Estatuto catalán. Otra posibilidad de salvar la competencia aragonesa sobre alteración de términos municipales podría consistir, siguiendo el modelo andaluz, en entender que se encuentra implícita en la materia de "organización territorial propia 84 de la Comunidad” atribuida a la plena competencia autonómica (art. 71.6 del Esta- 
tuto de Aragón), interpretación esta que se reforzaría con el dato de que el título VI del Estatuto de Aragón (arts. 81-87) se dedica justamente a la "organización territorial y gobierno local".

De cualquier manera, las iniciativas tendentes a corregir los mapas municipales autonómicos han sido escasas. Tan apenas cabe referir algunas propuestas en Cataluña, que han sido estudiadas por J. Burgueño (2004: 19-29), como las realizadas privadamente por LI. Casassas y J. Clusa (1981), que proponían pasar de 935 a 127 municipios, o las más modestas del Informe Roca (2000), que planteaba reducir el número de municipios catalanes de 946 entonces a 758. En Navarra, M. Izu Belloso (2007: 440-441) cita un proyecto del Departamento de Administración Local del Gobierno Foral de 1989 previendo una reforma de 265 a 124 municipios. Finalmente, para Galicia primero y después para toda España, el geógrafo R. Rodríguez González (2005) ha realizado una notable defensa de la reestructuración del territorio mediante fusiones de municipios.

La prioridad en las actuaciones relativas a la reforma del régimen local ha correspondido a la democratización del poder local y al establecimiento de garantías formales de la autonomía local entendida como ausencia de controles. El Estado no sólo ha omitido todo tipo de proyectos en relación con la reforma del mapa municipal, sino que en el Libro blanco para la reforma del gobierno local (2005: 69) se permite asegurar que "no es realista plantear la reducción del mapa municipal en aras de alcanzar dimensiones idealmente más eficaces” y ello no por ningún razonamiento, sino por la constatación de que "no ha habido en España verdaderos intentos de racionalización y simplificación del mapa municipal ni se vislumbran tampoco en el futuro inmediato"; es decir, para el Ministerio de Administraciones Públicas que suscribe el informe no es realista pretender hacer lo que hasta ahora no se ha hecho ni se ha pretendido hacer; así nos va. A renglón seguido, el Ministerio considera incluso que "tampoco debemos perder de vista los aspectos ventajosos de la existencia de un elevado número de municipios", ventajas "que van desde la existencia de más instituciones con representación democrática hasta la preservación del medio ambiente o del acervo histórico o cultural en el medio rural"; en definitiva, la España de los valores eternos mantenida en los pequeños municipios.

En la legislación básica de régimen local continúan favoreciéndose las segregaciones de partes de un término municipal para constituir nuevos municipios. No obstante, una pequeña variante se advierte con respecto a los planteamientos tradicionales, pues en el art. 13.2 de la Ley 7/1985 de Bases del Régimen Local ya no se vincula la suficiencia de los municipios resultantes de la segregación al cumplimiento de las competencias municipales mínimas (que son verdaderamente muy elementales: art. 26 LBRL), sino más ampliamente al "cumplimiento de las competencias municipales" y a que "no suponga disminución en la calidad de los servicios que venían siendo prestados". Tanto esa pequeña reorientación legal como la actitud más firme de las Comunidades Autónomas frente a las segregaciones han determinado una jurisprudencia mucho más estricta frente a los intentos de crear los denominados "munici- 
pios exiguos", como se advierte ya en la STS 4504/1996. Los requisitos legales determinantes de la segregación son ahora considerados como elementos mínimos pero no exclusivos, pues pueden conjugarse con otras circunstancias de interés público según se dice en la STS 282/2001, conforme a planteamientos que se reiteran en las SSTS 3034/2003, 1378/2004, 4628/2005, 4901/2008, 6891/2009 y 2302/2010 entre otras:

“... esos requisitos exigidos son sólo el presupuesto mínimo necesario e indispensable para que pueda tomarse en consideración un proyecto de creación, pero no significa que su existencia necesariamente conduzca a ello. La decisión final, debe implicar un margen de discrecionalidad, que permita valorar otros aspectos, por parte del órgano que tiene atribuida la competencia; por supuesto que ello no ha de suponer arbitrariedad, sino sólo el que deban entrar en juego esos otros aspectos que puestos en función del interés público prevalente justifiquen esa denegación."

Paralelamente ha de destacarse el paulatino establecimiento en la legislación autonómica de exigencias de una cifra mínima de habitantes para la creación de nuevos municipios. En el gráfico 6 se recogen las poblaciones mínimas exigidas, que van desde 500 habitantes en La Rioja (2003, en 1993 eran 350) a 5.000 habitantes en Galicia (1997), siendo la cifra más generalizada la de 1.000 habitantes (Navarra, 1990; CastillaLa Mancha, 1998; Castilla y León, 1998; Aragón, 1999; y Madrid, 2003), aunque se exigen 2.000 en Cataluña (1998), 2.500 en los territorios de Vizcaya y Guipúzcoa (1995 ambos) y 4.000 en Andalucía (1993). Se trata en todo caso de condicionamientos muy suaves pues en ningún caso se alcanza la media de población de los municipios españoles ni tampoco los valores medios de cada Comunidad Autónoma (tabla A).

\section{GRÁFICO 6}

Población mínima para nuevos municipios en la legislación de CC.AA.

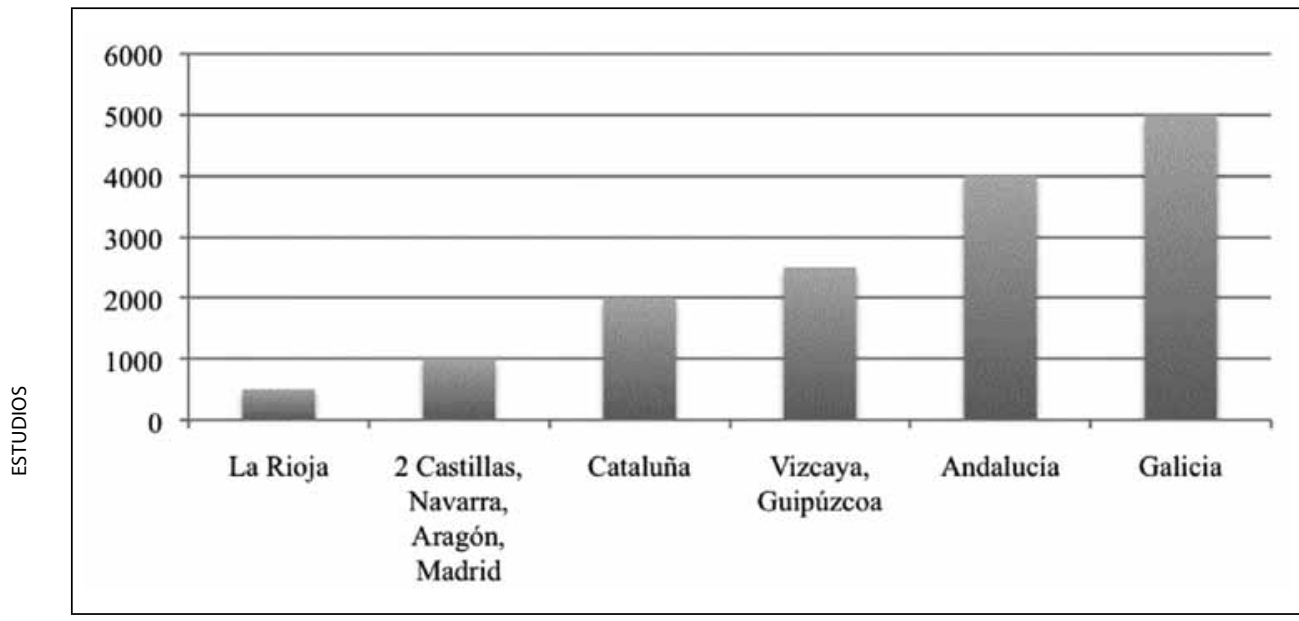

86 Fuente: elaboración propia. 


\section{B) Experiencias europeas}

Después de la Segunda Guerra Mundial, en diversos Estados de Europa se han desarrollado importantes políticas de fusión de municipios que han puesto fin a situaciones previas de alta fragmentación de los correspondientes sistemas de organización territorial. La literatura relativa a esas experiencias resulta en verdad notable, pudiendo citarse últimamente los estudios colectivos dirigidos por J. Meligrana (2004), que trata de diversas reformas de los mapas municipales en países de todo el mundo, y los publicados por Council of European Municipalities and Regions (2008), Dexia Reasearch Department (2008) y P. Swianiewicz (2010), que recogen referencias sobre los variados procesos de reforma de los límites municipales desarrollados en el ámbito de la Unión Europea. En castellano una publicación muy recomendable es el volumen dirigido por F. Velasco (2010), donde se exponen con minuciosidad los regímenes locales de tres Estados descentralizados europeos: Alemania, Italia y Reino Unido (para un resumen de las políticas de fusión de municipios en estos países: pp. 553-555). Aquí vamos a tratar brevemente de los casos de Suecia, Bélgica, Dinamarca y Grecia, que parecen suficientemente representativos de los procesos de diseño, aprobación y ejecución de amplias operaciones de reducción del número de municipios.

Suecia fue al parecer el Estado europeo que más tempranamente inició y completó las políticas de fusión municipal, que ocuparon un período de más de treinta años (1943-1977). El punto de partida eran 2.414 municipios basados en las antiguas parroquias para una población entonces de 6'49 millones de habitantes, lo que daba una población media/municipio de 2.689 habitantes, contabilizándose unos 500 municipios de menos de 500 habitantes.

En 1943 la comisión de expertos sobre la división municipal propuso una drástica reducción del número de municipios rurales, que resultaban altamente ineficaces, lo que determinó una primera ola de fusiones desarrollada hasta 1952. Los municipios rurales pasaron a ser 816 continuando con su estatuto especial las 133 ciudades reconocidas; en total, pues, 949 municipios, que para una población entonces de 7’12 millones de habitantes daban una media de 7.508 habitantes/municipio.

Nuevamente en 1959 la comisión de expertos recomendó formar un mayor número de municipios mixtos rural-urbanos con vistas a involucrar a las ciudades en el desarrollo equilibrado del territorio. En 1962 el Parlamento postuló llevar a cabo la reforma del mapa local sobre una base de voluntariedad por parte de los municipios. A fin de estimular las reformas, en 1964 el Gobierno agrupó a todos los municipios en 282 bloques cuya cooperación debía generar los nuevos municipios antes de 1971. Sin embargo, los resultados de los procesos de fusiones voluntarias únicamente produjeron en el período 1965-1969 la reducción de un centenar de municipios, cuyo número total pasó a ser 848 , que para una población de 7’96 millones de personas daba una media de 9.396 habitantes/municipio. 
Encontrando que el proceso resultaba demasiado lento, en 1971 el Parlamento decidió imponer las fusiones fijando el número total de municipios en 464, todos ellos dotados del mismo régimen jurídico al haberse suprimido las antiguas especialidades del estatuto de las ciudades. Para un total de 8'og millones de personas, la población media pasaba a ser de 17.452 habitantes/municipio.

Entre 1974-1977 un nuevo proceso de racionalización redujo el número de municipios a 278 para un total de 8'16 millones de personas, situándose la población media en 29.356 habitantes/municipio. En la actualidad, tras algunas segregaciones adoptadas siempre por decisión discrecional del Gobierno y conforme al criterio de que no puede existir ningún municipio de menos de 5.000 habitantes, existen 290 municipios para una población de 9'29 millones de habitantes, lo que determina una media de 32.065 habitantes/municipio.

En el gráfico 7 se ha representado la evolución de la población media/municipio a lo largo de este proceso sostenido por el partido socialdemócrata pero no cuestionado esencialmente por las restantes fuerzas políticas. Se ha producido así una importante transformación en la organización territorial sueca al haberse reducido el número de municipios 8'32 veces desde las cifras originales. No obstante, dada la gran superficie de estos municipios, que alcanzan la mayor superficie media europea (1.551'6 Km²; véase la tabla B), a efectos censales y electorales continúan reconociéndose como entes locales menores 2.512 parroquias.

\section{GRÁFICO 7}

Suecia, evolución de la población media/municipio

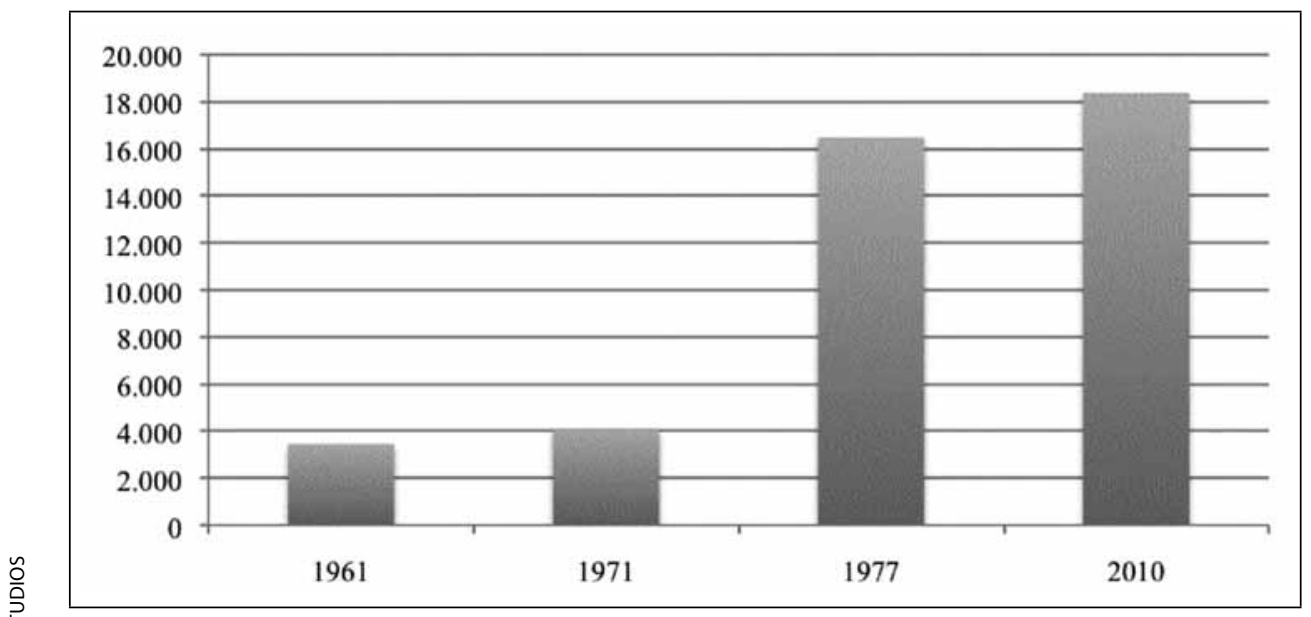

Fuente: elaboración propia.

En Bélgica el proceso de fusiones de municipios se desarrolló en el período 19611983. El punto de partida era un mapa municipal de 2.663 municipios para 9'18 millo88 nes de habitantes que daban una media de 3.448 habitantes/municipio. 
Considerando que tan pequeñas unidades carecían de capacidad para prestar los servicios considerados necesarios, en 1961 el Gobierno demócrata-cristiano estableció unas bases financieras, geográficas, lingüísticas, económicas, sociales y culturales para la formación de nuevos municipios de mayor tamaño. Sin embargo, las fusiones voluntarias en el período 1961-1971 supusieron la supresión de únicamente 304 municipios, de manera que quedaron 2.359 municipios para 9'69 millones de personas con una media de 4.109 habitantes/municipio.

En 1971, el Gobierno de coalición de liberales y demócrata-cristianos, con el acuerdo de la oposición socialista, puso en marcha un proceso de fusiones municipales obligatorias (plan Costard de 1972). La formación de estos grandes municipios se consideró justificada en los cambios sociales producidos por la urbanización del país y por la reducción de distancias derivada de la mejora en las comunicaciones. Se procuró en todo caso que las nuevas divisiones generaran movimientos de recíproca solidaridad entre las ciudades (proveedoras de servicios cuya prestación requiere una cierta escala) y los frecuentemente ricos núcleos de población de su entorno (contribuyentes en el sostenimiento financiero de la entidad municipal compleja).

Para evitar resistencias locales, la reforma se desarrolló con rapidez, de manera que en 1977 la organización territorial se consolidó con la formación de 596 municipios que, para una población de 9'83 millones de habitantes, determinaban una media de 16.493 habitantes/municipio. Tras algunos ajustes, en la actualidad hay 589 municipios con una población media de 18.382 habitantes/municipio, más de tres veces superior a la europea, y con una superficie media de 51 '37 Km².

\section{GRÁFICO 8}

Bélgica, evolución de la población media/municipio

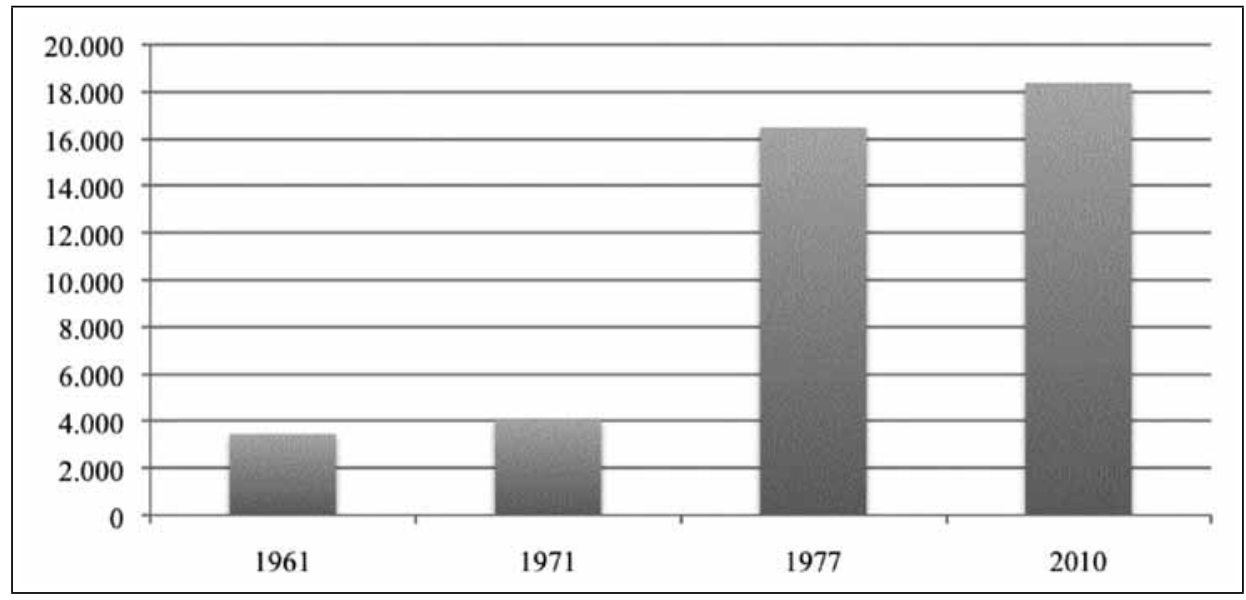

Fuente: elaboración propia.

En el gráfico 8 queda reflejada la evolución de las poblaciones medias de los municipios belgas, que han experimentado un aumento de 5'3 veces con respecto a 
las cifras iniciales. Ahora bien, si los nuevos municipios cuentan con medios humanos y económicos suficientes, conviene tener en cuenta que las fusiones no fueron acompañadas de un incremento sensible de los poderes locales. Ello explica que la positiva percepción general del proceso sea compatible con la consideración de la escasa participación local en la toma de decisiones. Incluso las elecciones municipales, que anteriormente se desarrollaban al margen de los grandes partidos políticos nacionales, han pasado a cobrar una dimensión estatal.

En Dinamarca se han desarrollado dos procesos de fusiones municipales, el primero en 1960-1970 y el segundo en 2002-2007. Previamente existían 1.389 municipios que para 4'5 millones de habitantes suponían una media de 3.298 habitantes/municipio.

La primera reforma se preparó cuidadosamente por Gobiernos social-demócratas a lo largo de diez años contando con un amplio consenso político. Consistió en fusionar los antiguos municipios y condados creando sólidas unidades de gobierno local por cada área urbana dotadas de amplios poderes y capacidades financieras al sustituirse las subvenciones finalistas por transferencias generales. En 1970 se pasó así a constituir 271 nuevos municipios, que en un país de 4'9 millones de habitantes determinaban una media de 18.269 habitantes/municipio.

La segunda reforma se planteó de manera un tanto sorprendente por la coalición liberal-conservadora en 2002-2004 sin el pleno acuerdo de los partidos de la oposición aunque apoyándose en autoridades locales deseosas de obtener mayores responsabilidades y también en la postura favorable o indiferente de la opinión pública, que asumió el carácter puramente técnico de la operación. Las razones determinantes de las nuevas fusiones de municipios fueron en efecto los beneficios de las economías de escala, es decir, la mejora en la calidad y la eficiencia de los servicios públicos. Así, en 2004 el proyecto salió adelante con el exclusivo apoyo parlamentario de los partidos de la coalición de gobierno, y en 2007 se pasó a un mapa integrado únicamente por 98 municipios con una población media de 55.724 habitantes/municipio, en la actualidad 56.479 habitantes/municipio, una de las más elevadas de la Unión Europea.

En el gráfico 9 puede observarse la evolución experimentada en las poblaciones medias de los municipios daneses desde 1960, que suponen un incremento de más de 17 veces. Los gobiernos municipales han pasado a ser los primeros proveedores de servicios del sector público disfrutando de amplias competencias en materias de salud, empleo, servicios sociales y educación especial, medio ambiente, urbanismo, transporte público, cultura, desarrollo local, puertos, aeropuertos... Constituyen los puntos de acceso del ciudadano al sector público.

Finalmente en Grecia ha habido también dos programas de fusiones municipales en 1997 y 2010. El cuadro inicial estaba formado por 5.825 municipios con una media poblacional de 1.828 habitantes/municipio dentro de una fuerte tradición centralista que determinaba la formación de redes clientelares para la atención de las demandas locales. Las cohesiones locales se fundaban en un fuerte sentido de la identidad que 90 personificaban los alcaldes elegidos directamente. 


\section{GRÁFICO 9}

Dinamarca, evolución de la población media/municipio

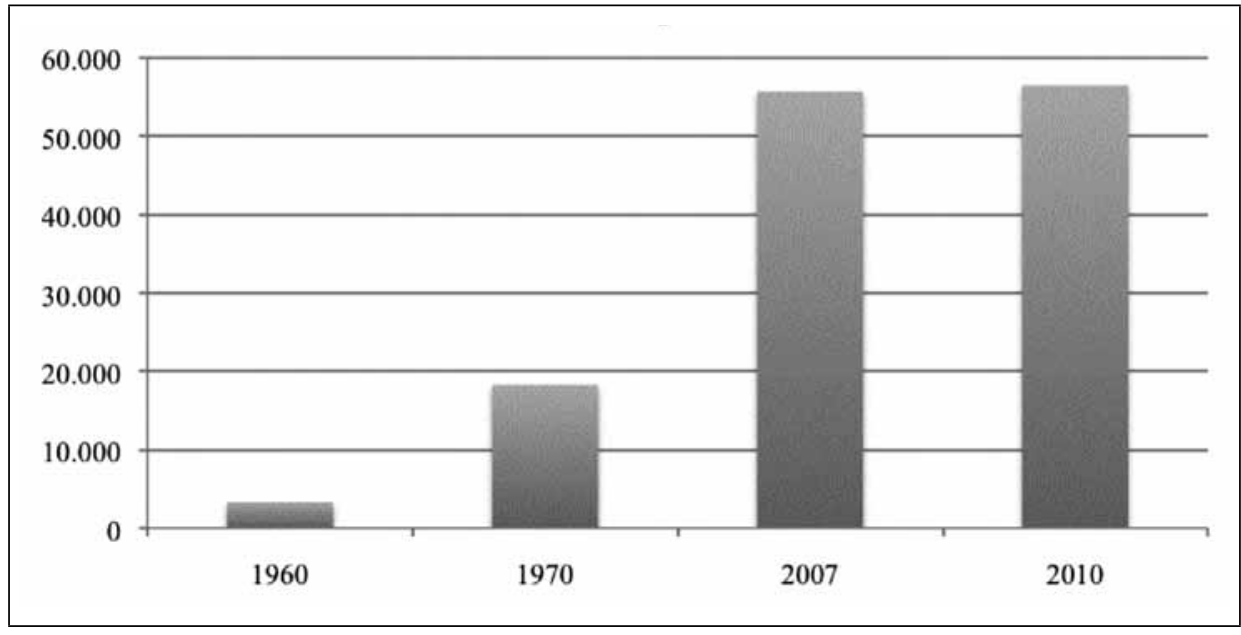

Fuente: elaboración propia.

En 1997 el Gobierno socialista, modificando sus posturas previas en contra de las fusiones obligatorias, aprobó el plan Kapodistrias con el objetivo de formar municipios fuertes dotados de mayores competencias, capaces de prestar modernos servicios a los ciudadanos y de constituirse en promotores del desarrollo local. La difusión de ideas de modernización y europeización del país permitió que la opinión pública y el personal político estuvieran inicialmente a favor de las reformas, pese a la oposición conservadora y la generada en algunos ámbitos locales, que se manifestó incluso en esporádicos episodios de violencia. Así, en 1999 se pasó a formar 1.033 municipios con una media de 10.310 habitantes/municipio.

A pesar de la posterior prevalencia de sentimientos populares contrarios a las reformas locales debido a la frustración de las expectativas que se habían generado, en 2007 el Gobierno conservador, cambiando anteriores puntos de vista, planteó nuevas reformas del mapa local. En el proyecto Kallikratis se diseñan unos nuevos gobiernos locales basados en el ahorro de costes, la descentralización, la modernización, la transparencia y la responsabilidad, planteando tales características como exigencias de la Unión Europea ante la crisis económica. El resultado habría de ser la formación de 370 municipios, que alcanzarían una población media de 30.433 habitantes/municipio.

En el gráfico 10 se ha recogido la espectacular evolución de la planta municipal griega. No obstante, los últimos planes se sitúan, como es conocido, en un contexto de profunda crisis económica e inestabilidad social que hace dudar del pleno éxito en los resultados finales. Los empleados públicos y los políticos locales que habrían de quedar desplazados mantienen actitudes fuertemente beligerantes que hacen temer la generación de un cierto caos administrativo en la puesta en marcha de las nuevas autoridades. 
GRÁFICO 10

Grecia, evolución de la población media/municipio

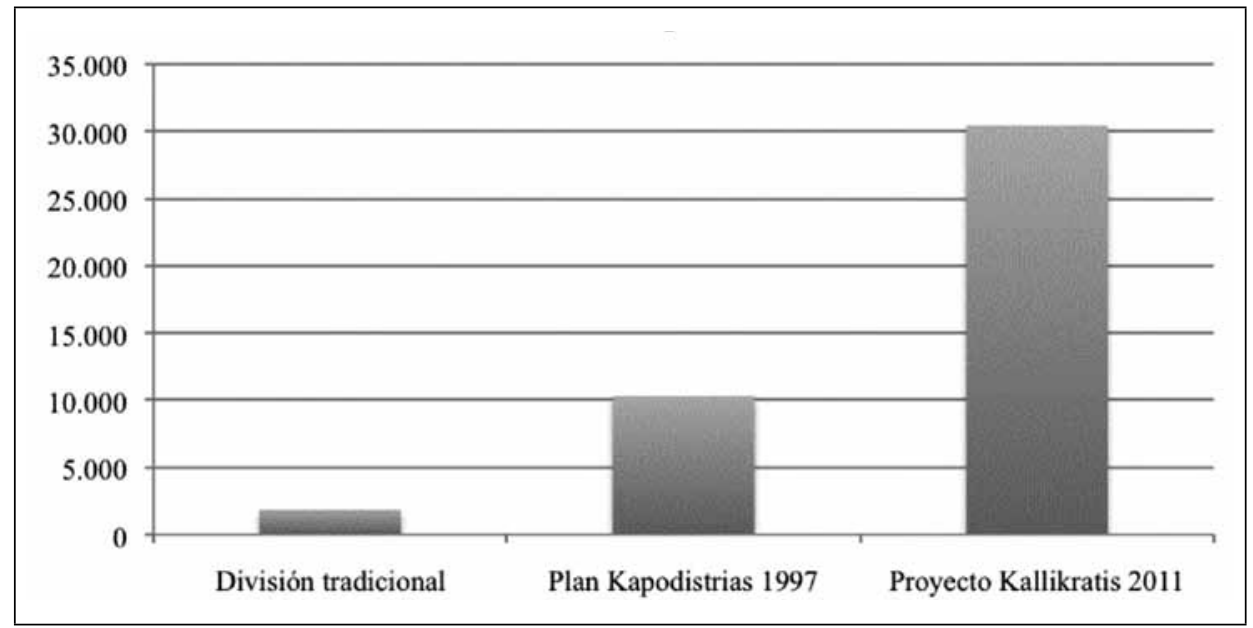

Fuente: elaboración propia.

Las anteriores experiencias europeas permiten identificar dos grandes líneas de actuación: a) la primera, desarrollada enteramente en Suecia y Bélgica y parcialmente en las iniciales reformas de Dinamarca y Grecia, se caracteriza por un alto consenso político nacional y la aplicación de calendarios amplios, como operaciones de Estado en definitiva, guiándose por ideas de ordenación del territorio que implican una apuesta por el desarrollo solidario entre las ciudades y las áreas rurales de su entorno; y b) la segunda es la impuesta más recientemente desde mayorías de gobiernos conservadores en Dinamarca y Grecia, que obedecen preferentemente a planteamientos económicos dominados por la búsqueda de la eficiencia en el gasto local. Si se acepta la anterior síntesis, habría de destacarse que, bajo la óptica de los grandes desequilibrios del territorio español, parecería quimérica la pretensión de reformar nuestro mapa local para ahorrar costes. En los municipios despoblados y envejecidos de la Celtiberia profunda ni se gasta nada ni hay nada que gastar. La organización del territorio aparece así enhebrada a las exigencias de la ordenación territorial, que imponen sin duda la previsión de programas de inversiones locales para acercar la teoría del Estado Social a la realidad de nuestro mundo rural.

\section{LA COMARCALIZACIÓN COMO VÍA ALTERNATIVA}

Ante las dificultades prácticas que plantean las fusiones, la constitución de comarcas conforma una propuesta tradicional en la literatura española para solucionar las carencias de los pequeños municipios. En los estudios, entre otros, de R. Martín Mateo (1964), F. Albi (1966) y L. Morell Ocaña (1972), la comarca se concibió como un

92 ente local autónomo de segundo grado formado por la agrupación de diversos muni- 
cipios con la finalidad esencial de cooperar en la prestación de los servicios municipales. Finalidad que habría de compartir con la provincia, determinando una potencial falta de encaje entre ambas instituciones.

Actualmente contamos ya con diversas experiencias sobre la figura comarcal en las Comunidades Autónomas (G. García Álvarez, 2005: 71-92; A. Sánchez Blanco, 2006: 100-188). A la vista de las mismas, ante todo, habría que diferenciar entre las comarcas que se configuran como entidades locales autónomas y las comarcas entendidas como ámbitos de la planificación territorial o de la organización periférica de la Administración autonómica, planteamientos estos últimos que cabe encontrar en relación con los planes subregionales de ordenación del territorio de Andalucía (Ley de Ordenación del Territorio 1/1994), los planes de desarrollo comarcal de Galicia (Ley de Desarrollo Comarcal 7/1996) y las denominadas “demarcaciones de La Rioja” (Ley de Administración Local 1/2003).

En las Comunidades Autónomas que han regulado las comarcas como entidades supramunicipales dotadas de autonomía, se advierten hasta tres ritmos en los correspondientes procesos de implantación: a) comarcas cuya creación exige la voluntad de todos los municipios implicados, de manera que están sin constituir, como sucede en Asturias (Ley 3/1986, que regula el procedimiento de creación de comarcas) y Cantabria (Ley de Comarcas 8/1999); b) comarcas implantadas únicamente en una parte del territorio autonómico cual sucede con la Comarca de El Bierzo creada por la Ley de Castilla y León 1/1991; y c) comarcas creadas conforme a un mapa comarcal establecido para todo su territorio por la Comunidad Autónoma sin perjuicio de la previsión de correcciones en el mismo a iniciativa de los municipios, tal y como se advierte en Cataluña y Aragón.

La opción catalana (Ley 6/1987) de reproducir la división comarcal establecida durante la Segunda República obligó posteriormente a introducir correcciones en los límites de 25 de las 41 comarcas (Leyes 5/1988 y 3/1990) y a establecer mejoras organizativas como la creación de los consejos comarcales de alcaldes (Ley 8/2003). En el Informe Roca (2000) sigue planteándose la necesidad de ajustes importantes, que afectan tanto al mapa comarcal como a la definición de las relaciones de las comarcas con las diputaciones provinciales por arriba y con los municipios por abajo.

Vamos a fijarnos especialmente en las comarcas aragonesas, cuyo régimen jurídico ha sido ya analizado en el conjunto de trabajos dirigidos por R. Salanova (2002). La comarcalización en Aragón se presentó como una vía adecuada de lucha contra los problemas del minifundismo municipal y la despoblación. Se pretendía que las comarcas sirvieran para suplir las carencias de los municipios, ofreciendo un tamaño más adecuado que garantizara la prestación de servicios sanitarios, educativos, de transporte, ambientales y otros. Por otra parte, el mantenimiento inalterado de la planta municipal habría de evitar que la comarcalización contribuyera al incremento de la desertización territorial.

El proceso de implantación de las comarcas ha avanzado paulatinamente bajo el impulso político dominante del Partido Aragonés, que ha sabido ganar el apoyo de las 
restantes fuerzas políticas. Las bases iniciales probablemente deban ser situadas en la política de fomento de las mancomunidades intermunicipales (Ley 6/1987). En la III Legislatura autonómica se aprobó la Ley de Comarcalización 10/1993 estableciendo el marco procedimental, competencial, organizativo y financiero para la constitución de las comarcas. En la IV Legislatura se aprobó la Ley de Delimitación Comarcal 8/1996, que estableció con carácter indicativo el mapa comarcal, tras un complejo periodo de consultas.

Al mismo tiempo, se inició la reforma de los servicios periféricos de la Administración de la Comunidad Autónoma adaptándolos a la división comarcal, operación que resultó particularmente visible en el caso de las estructuras agrarias al agruparse en unidades comarcales las antiguas agencias de extensión agraria, las zonas veterinarias, las cámaras agrarias locales y la guardería forestal (Decreto 71/1997). En ese mismo sentido, en la V Legislatura se comenzó promoviendo de manera general la reorganización conforme a bases comarcales de la Administración periférica (Decreto 74/2000). El apoyo de las Cortes de Aragón a la iniciativa se buscó mediante el envío por el Gobierno de la "Comunicación sobre la Administración de la Comunidad Autónoma ante el proceso de comarcalización" (BOCA de 25 octubre 2000), comunicación que determinó la aprobación de un conjunto de resoluciones parlamentarias en apoyo del proceso (BOCA de 4 julio 2001).

Dentro de la V Legislatura aragonesa se aprobó también la Ley de Medidas de Comarcalización 23/2001 en la que se detallan las competencias correspondientes a las comarcas. Cada una de las materias genéricamente reservadas a las comarcas en la Ley de Comarcalización 10/1993 fue pormenorizadamente analizada en la Ley de Aragón 23/2001, transformándose en concretas y exactas competencias que podrían ser asumidas por los entes comarcales. Junto a ello, se establecieron principios sobre el alcance de las competencias comarcales, reglas para la transferencia de los servicios correspondientes y algunas medidas complementarias. En la actualidad, esas Leyes $10 / 1993$ y 23/2001, junto con las modificaciones parciales que se habían introducido en las mismas especialmente por la Ley $3 / 2006$, se encuentran incluidas en el Texto Refundido de la Ley de Comarcalización (Decreto legislativo 1/2006).

A lo largo de la V y VI Legislaturas autonómicas, entre los años 2000 y 2003 se procedió a la aprobación de las leyes de creación de 32 comarcas, quedando pendiente de constitución la referida a Zaragoza y su entorno metropolitano. El mapa comarcal se ha ajustado en términos generales a la Ley de Delimitación Comarcal 8/1996, aunque al haberse reconocido un significativo papel en el proceso a los municipios afectados, las leyes de las comarcas han introducido correcciones que finalmente se han incorporado al Texto Refundido de la Ley de Delimitación Comarcal (Decreto legislativo 2/2006). En el proceso de comarcalización quedó, así, depositada una parte significativa de las esperanzas de transformación del territorio aragonés. Las comarcas aragonesas pueden considerarse de origen y sustancia municipales, pues han sido creadas por iniciativa de los municipios cuyos representantes integran al mismo 94 tiempo los órganos de gobierno comarcales. 
En la tabla $C$ se han recogido algunos datos que permiten comprobar la realidad comarcal aragonesa sin incluir la futura Comarca de Zaragoza, que con sus 743.280 habitantes probablemente habría de requerir una ordenación especial como área metropolitana.

TABLA C

Comarcas de Aragón

\begin{tabular}{|l|c|c|c|c|}
\hline \multicolumn{1}{|c|}{ Comarca } & Población & $\begin{array}{c}\text { Superficie } \\
\left(\mathbf{K m}^{2}\right)\end{array}$ & $\begin{array}{c}\text { Número de } \\
\text { Municipios }\end{array}$ & $\begin{array}{c}\text { Presupuesto } \\
\text { 2009 (miles } \boldsymbol{\epsilon})\end{array}$ \\
\hline Hoya de Huesca & 67.992 & 2.518 & 40 & 9.175 \\
\hline Comunidad Teruel & 47.361 & 2.791 & 46 & 4.751 \\
\hline Comunidad Calatayud & 42.209 & 2.518 & 67 & 5.444 \\
\hline Cinco Villas & 33.580 & 3.062 & 31 & 4.906 \\
\hline Valdejalón & 30.380 & 933 & 17 & 4.923 \\
\hline Bajo Aragón & 30.370 & 1.304 & 20 & 4.444 \\
\hline Ribera Alta del Ebro & 27.810 & 416 & 17 & 4.953 \\
\hline Bajo Cinca & 24.663 & 1.419 & 11 & 4.874 \\
\hline Somontano Barbastro & 24.536 & 1.166 & 29 & 6.032 \\
\hline Cinca Medio & 24.007 & 576 & 9 & 4.961 \\
\hline Los Monegros & 21.340 & 2.764 & 31 & 6.873 \\
\hline La Litera & 19.291 & 733 & 14 & 5.626 \\
\hline La Jacetania & 18.703 & 1.857 & 20 & 6.901 \\
\hline Campo de Borja & 15.621 & 690 & 18 & 3.882 \\
\hline Alto Gállego & 14.916 & 1.359 & 8 & 5.099 \\
\hline Tarazona y Moncayo & 14.825 & 452 & 16 & 3.086 \\
\hline Bajo Aragón-Caspe & 14.775 & 997 & 6 & 3.262 \\
\hline Jiloca & 14.442 & 1.932 & 40 & 5.185 \\
\hline La Ribagorza & 13.177 & 2.459 & 34 & 5.844 \\
\hline Andorra-Sierra Arcos & 11.601 & 675 & 9 & 2.992 \\
\hline Campo de Cariñena & 11.214 & 772 & 14 & 4.059 \\
\hline Ribera Baja del Ebro & 9.333 & 989 & 10 & 3.293 \\
\hline Cuencas Mineras & 9.269 & 1.407 & 30 & 3.312 \\
\hline Matarraña & 8.943 & 933 & 18 & 4.096 \\
\hline Gúdar-Javalambre & 8.792 & 2.351 & 24 & 3.470 \\
\hline Sobrarbe & 7.764 & 2.202 & 19 & 5.365 \\
\hline Aranda & 7.696 & 561 & 13 & 2.431 \\
\hline Bajo Martín & 7.255 & 795 & 9 & 4.042 \\
\hline Campo de Daroca & 6.322 & 1.117 & 35 & 3.644 \\
\hline Campo de Belchite & 5.288 & 1.043 & 15 & 2.257 \\
\hline Sierra de Albarracín & 4.968 & 1.414 & 25 & 2.712 \\
\hline Maestrazgo & 3.780 & 1.204 & 15 & 3.036 \\
\hline
\end{tabular}

Fuente: elaboración propia con datos de Portal de las Comarcas de Aragón, 2010. 
a) Población. La población de las comarcas aragonesas, con cifras del año 2009, va de los 3.780 habitantes del Maestrazgo, la más despoblada, a los 67.992 de la Hoya de Huesca, ofreciendo una población media de 18.818 habitantes/ comarca y situándose las diferencias demográficas entre comarcas en una escala de 1 a 18.

b) Superficie. Las diferencias en la superficie de las comarcas aragonesas van desde los $3.062 \mathrm{Km}^{2}$ de las Cinco Villas a los $416 \mathrm{Km}^{2}$ de la Ribera Alta del Ebro recorriendo una escala de 1 a 7'3 y con una superficie media de $1.420 \mathrm{Km}^{2} /$ comarca.

c) Municipios. El número de municipios integrado en cada comarca varía desde los 6 del Bajo Aragón-Caspe a los 67 de la Comunidad de Calatayud, ofreciendo una media de 22 municipios/comarca en una escala de 1 a 11'1.

d) Presupuestos. En el año 2002, el coste de las funciones y servicios a transferir a las comarcas alcanzaba la valoración de 128'3 millones de euros y las dotaciones correspondientes a los costes de personal asociados al ejercicio de las competencias suponía un total cercano a los 0'7 millones euros (anexo de la Ley 23/2001). En el año 2009, la suma de los presupuestos de gastos de las comarcas alcanzaba la cifra de 145 millones de euros, correspondiendo el presupuesto más bajo a Campo de Belchite (2'25 millones) y el más alto a la Comunidad de Calatayud (5'44 millones), en una escala de 1 a 2'4.

e) Procedencia de ingresos. En cuanto a la procedencia de los ingresos, en el año 2005 se distribuían en los siguientes porcentajes: 78'41\% transferencias de la Comunidad Autónoma, 9'81\% transferencias de entidades locales, 6'04\% impuestos, tasas y precios públicos y 5 '74\% otros ingresos.

f) Personal. El personal de las comarcas aragonesas estaba formado por unos 2.250 empleados en el año 2010, el $85 \%$ de los cuales se dedica a labores de prestación de servicios y el $15 \%$ a tareas burocráticas.

g) Servicios. Las comarcas aragonesas prestan efectivamente servicios en materia de acción social (mayores, mujeres, menores), lucha contra incendios, protección civil, cultura, promoción del turismo, protección del patrimonio cultural, transportes, deporte, ordenación del territorio, urbanismo y tutela del medio ambiente.

A la vista de las informaciones anteriores, parece claro que las comarcas se han asentado en el territorio aragonés. Para llegar a ello, ha sido decisiva la constante y firme voluntad del Gobierno de Aragón a lo largo de un período de formación que ha ocupado diez años (1993-2003). Durante el mismo se ha sabido combinar la dirección 96 del proceso según el plan trazado con la previsión de incentivos económicos generosos y la apertura a la participación de los municipios afectados. La delimitación co- 
marcal ha sido rápidamente aceptada, lo que sin duda es un mérito que cabe atribuir a todos los partidos políticos y a toda la clase política aragonesa, tanto en el ámbito autonómico como en el local.

Sin embargo, la idea inicial de configurar unas comarcas que cooperaran con los municipios, que salvaran de su decrépita situación a los centenares de ayuntamientos aragoneses incapaces de valerse por sí solos, parece estar lejos de ser una realidad. La gran mayoría de los pequeños municipios vegeta sin tan apenas poder sostener una secretaría compartida. Las comarcas funcionan, sí, pero ante todo prestando sus propios servicios, y no tanto como uniones de municipios, sino más bien como ámbitos de reparto de poder de los partidos políticos. En este sentido la situación de las comarcas aragonesas quizá no sea muy diferente de la descrita por M.A. Aparicio (2003: 154) en relación con las vecinas comarcas catalanas, donde éstas "han servido y sirven como tablero de reparto desigual de las cuotas de poder político y social de los distintos partidos y agrupaciones políticas en presencia", concurriendo el dato característico de que "los consejos comarcales y su presidente no representan ni a los ciudadanos ni a los municipios", pues "son elegidos directamente por los partidos y agrupaciones políticas en función del número de concejales que han obtenido".

La configuración de Administraciones públicas con funciones asistenciales de otras Administraciones plantea siempre problemas de muy difícil solución. La práctica de las tareas institucionales de cooperación con los municipios produce con frecuencia y no siempre sin fundamento sentimientos de desigualdad en el reparto de los recursos. De ahí la tendencia a incrementar los servicios propios con desatención a las necesidades primarias de municipios. Esa tendencia se puede observar fácilmente en la trayectoria de las provincias, cuya época de esplendor coincidió con la instauración de aquellos servicios provinciales (hospital, maternidad, hospicio, manicomio, laboratorio de higiene, servicio de carreteras, etc.) que tanto contrastaban en el contexto de la España pobre y caciquil de la Restauración (López Ramón, 1991: p. 353); a medida que los servicios provinciales fueron fagocitados por los modernos sistemas estatales de seguridad y asistencia social, la provincia fue perdiendo su rumbo.

Las comarcas buscan el propio ámbito de desenvolvimiento al margen de los municipios, pues así evitan chocar con el límite de la autonomía comarcal que deriva del necesario respeto a las competencias municipales. En tal sentido, el art. 42.4 de la Ley Básica del Régimen Local de 1985 estableció expresamente:

"La creación de las comarcas no podrá suponer la pérdida por los municipios de la competencia para prestar los servicios enumerados en el artículo 26, ni privar a los mismos de toda intervención en cada una de las materias enumeradas en el apartado 2 del artículo 25."

El precepto fue impugnado por las Comunidades Autónomas de Galicia y Cataluña, que propugnaban la viabilidad de ejercer sus competencias sobre alteraciones municipales para constituir municipios-comarca, esto es, comarcas nutridas de competencias de los municipios; y ello con el argumento de que si las Comunidades Autó- 
nomas eran competentes para suprimir municipios con mayor razón lo eran para establecer traspasos de competencias de los municipios a las comarcas.

Pues bien, en la STC 214/1989, de 21 diciembre, se rechazó la inconstitucionalidad del precepto controvertido con un complejo razonamiento [FJ 13.C)]. Se admitió, primero, que la garantía institucional del municipio no se refiere a la preservación de cada municipio, de manera que el art. 42.4 de la Ley Básica del Régimen Local no serviría para condicionar las alteraciones de los términos municipales acordadas por las Comunidades Autónomas. Sin embargo, a continuación, se afirmó también que la norma en cuestión "garantiza la institución municipal, que, aun en la hipótesis extrema, no podrá diluirse para llegar a identificarse con la comarca”; “impide, en efecto, la materialización del supuesto último del municipio-comarca, de manera que por muy profundas que pudieran llegar a inclinarse esas alteraciones municipales no podrá llegarse a semejante situación".

Hemos de suponer que el TC no rechazó una eventual política autonómica de transformación de las comarcas en municipios, sino más bien lo que se le había propuesto por las Comunidades Autónomas recurrentes, esto es, el traspaso a las comarcas de competencias propias de los municipios. En otro caso, la garantía institucional del municipio estaría comprendiendo nada menos que el mapa municipal, que no podría ser sensiblemente alterado. Ahora bien, en cualquier caso, la doctrina constitucional reafirma el postulado de que las competencias comarcales limitan con las municipales. En consecuencia, quizá ya no resulte sorprendente el desarrollo de nuevos e imaginativos servicios y actividades comarcales a pesar de que en el mismo ámbito territorial no estén cubiertos los servicios municipales básicos.

Se plantea, así, una situación paradójica en la que las comarcas se añaden a las provincias como entes asistenciales de los municipios, pero sin que ni unas ni otras remedien las profundas carencias de tantos inframunicipios. Los servicios supramunicipales terminan beneficiando con frecuencia a las capitales de provincia o de comarca, sin incidir notablemente en las restantes poblaciones de las correspondientes demarcaciones. Mientras tanto, la dependencia municipal con respecto a los servicios centrales y periféricos de la Administración de la Comunidad Autónoma crece, de manera que es en esos servicios donde se adoptan las decisiones relativas a las actividades que se desenvuelven en el territorio, sin rastro de autonomía local.

Pese a las limitaciones que plantean las comarcas en relación con los problemas de los pequeños municipios, conviene subrayar que la operación comarcal ha constituido un gran éxito en la organización territorial de la Comunidad Autónoma de Aragón. Quizá cabría incluso plantearse la posibilidad no ya de conformar unas comarcas-municipio, sino más bien de partir del mapa comarcal -que en general puede considerarse aceptado- para diseñar un nuevo mapa municipal. Si no todas, bastantes comarcas podían integrar en su seno a los municipios existentes para formar nuevos municipios que unieran las capacidades brindadas conjuntamente por el tamaño 98 de la comarca y por los poderes del municipio. 


\section{REFLEXIONES FINALES}

A la vista de los datos y consideraciones expuestos, parece obligado concluir que la formación de municipios fuertes requiere de un plan de actuaciones que prevea, en uno u otro momento, las fusiones obligatorias. Las fórmulas alternativas no acaban de solucionar el problema: a) las fusiones voluntarias resultan demasiado lentas en su producción y ofrecen escasos resultados, tanto si se considera el número absoluto de municipios afectados como si se valoran las entidades resultantes; b) las mancomunidades intermunicipales tienden a depender excesivamente, en su gestación y en su desarrollo, de los poderes públicos superiores, además de ofrecer el permanente foco de tensiones que supone la posibilidad de su desgajamiento; y c) las comarcas manifiestan una proclividad a generar su propia dinámica, que pudiera ser complementaria de los municipios, pero que de cualquier manera parece ajena a los mismos o deja, al menos, sin cubrir amplias parcelas de la vida local. Son tales circunstancias las que permiten explicar las operaciones de cirugía reconstructiva que vienen experimentado los mapas municipales en diversos países europeos.

Ahora bien, lograr un tamaño adecuado de los municipios no debiera considerarse como un fin en sí mismo, sino más bien como el medio para sostener un territorio vertebrado autónomamente, esto es, organizado en entidades locales democráticas, y capaces de realizar las infraestructuras y de prestar los servicios que se requieren para el desarrollo territorial equilibrado. Sin esa premisa, los intentos de fortalecer la autonomía local se harán en buena medida en el vacío, beneficiando únicamente a los vecinos de los municipios que de verdad existen. Organización y ordenación del territorio son políticas que han de ir unidas para conseguir la formación de municipios autónomos y fuertes, aptos para convertirse en motores del desarrollo local.

Las poblaciones que generaron las complejas relaciones económicas, sociales y culturales de nuestros pueblos se han trasladado en gran medida a las ciudades por causas variadas, que probablemente se resumen, de una parte, en la valoración económica de los conglomerados urbanos como foco de atracción y, de otra, en las aspiraciones de mejorar la calidad de vida de los propios emigrantes. Así, los procesos migratorios contemporáneos vienen desenvolviéndose en la península debido a la incidencia de fuerzas exteriores a los pueblos afectados, como pueden ser las concentraciones industriales, las expropiaciones eléctricas, o las carencias en las comunicaciones y en los servicios, causas que generan el fenómeno migratorio en unión de la voluntad de las personas afectadas de progresar individual y familiarmente, y ello aun a costa del desarraigo y la frustración que en tantas ocasiones han acompañado a estas experiencias.

La corrección del resultado de esas corrientes migratorias, esto es, de los desequilibrados mapas municipales de una gran parte del territorio español, sólo parece que pueda ser sostenible si parte de las propias comunidades afectadas. En otro caso, la promoción del desarrollo rural por impulsos externos produce escasos efectos positivos y de débil permanencia temporal. La única esperanza de reequilibrio 
territorial es la que puede proceder de las mismas colectividades afectadas. De ahí la necesidad de que estas comunidades se organicen en municipios fuertes.

Sin embargo, en abierto contraste con la paupérrima situación de nuestros municipios rurales, cabe prever que de ellos mismos provengan fuertes resistencias a la pérdida de su personalidad jurídica. No les faltaría razón para reaccionar ante proyectos de operaciones quirúrgicas cuya única finalidad fuera la formación de eficientes entidades administrativas sin prestar atención al equilibrio territorial. En tal tesitura, puestos a tener que ir desapareciendo, es lógico que las envejecidas poblaciones de los pequeños municipios prefieran hacerlo con la dignidad que les otorga el reconocimiento jurídico de su existencia. La legitimidad de tal postura no queda ensombrecida por la circunstancia de que intereses menos nobles pudieran confluir en los intentos de mantener el statu quo de nuestros municipios. Ciertamente es imaginable, en tal sentido, que pudieran identificarse en determinados estratos de la clase política y de la burocracia ese tipo de actitudes poco estimables, que lleguen incluso a prolongar artificialmente la agonía de tantos entes moribundos, por ejemplo, mediante un hábil manejo de los padrones municipales. Pero en todo caso, el caldo de cultivo que hace posible la oposición local a las fusiones de municipios tiene fundamento, por lo que, mientras no ataquemos la causa, el problema persistirá.

Por añadidura, en muchas ocasiones las resistencias de los pueblos a desaparecer como entidades jurídicas no sólo podrían derivan de la inquietud que genera la falta de un horizonte claro, sino particularmente de la prevención ante una vida futura conducida por el municipio vecino, objeto de particulares relaciones de amor y odio. También aquí, por tanto, la sabiduría popular tendría sus buenas razones para oponerse a una fusión que pudiera conllevar el sometimiento al núcleo urbano más poderoso del entorno. Puestos a padecer algún tipo de tiranía territorial, quizá pueda resultar preferible la imperial a la feudal.

Frente a tales posiciones eventuales de las poblaciones afectadas por procesos de fusión de municipios aún cabe imaginar una reacción que podríamos calificar de coyuntural, consistente en establecer medios para controlar o sorprender a la opinión pública y a los políticos locales. Con independencia de su moralidad, ese tipo de estrategias parece abocado al fracaso, dada la facilidad que las nuevas tecnologías brindan para forjar nuevos líderes y robustecer procesos de resistencia. Por ello, tal y como venimos sosteniendo, parece aconsejable actuar uniendo los poderes de organización del territorio con los de ordenación del mismo.

Ambos poderes confluyen en las Comunidades Autónomas, que son competentes para formar los respectivos mapas municipales (organización del territorio) y para corregir los desequilibrios producidos por el espontáneo crecimiento económico (ordenación del territorio). No obstante, cabría una implicación estatal en la materia al amparo de la competencia sobre las bases del régimen jurídico de las Administraciones Públicas (art. 149.1.18 a de la Constitución) con la finalidad de proporcionar 100 soporte jurídico, guías de actuación y estímulos a las políticas de reforma de los ma- 
pas municipales de las Comunidades Autónomas. La intervención sobre el tamaño de los municipios podría, así, concebirse como el inicio de un profundo proceso de reforma territorial: la puesta en marcha de la fase municipal de construcción del Estado de las autonomías. Y ello, desde el entendimiento de la reforma del mapa municipal no como un fin en sí mismo, sino como el medio de que los ciudadanos afectados puedan tomar las riendas de su futuro y luchar por la mejora de sus condiciones de vida. Operación que requiere de una firme voluntad política de tratar el problema del mapa municipal como la base de la construcción de verdaderos poderes locales. Por eso cabe pensar que estamos ante una cuestión de Estado, tanto en el ámbito central como en los ámbitos autonómicos.

Hablo, en efecto, de una operación de Estado consistente en poner en marcha auténticos poderes municipales, en diseñar el sistema de las autonomías locales sobre bases reales, estableciendo municipios que de verdad, todos, pudieran ser autónomos en todo el territorio nacional. Entre otros aspectos, cabría establecer con carácter básico un tamaño mínimo de los municipios españoles: la cifra de 5.000 habitantes pudiera ofrecerse en tal sentido como lógica, dado que resulta cercana a la actual población media/municipio del Estado (5.765 habitantes), y cuenta con precedentes en la legislación sectorial (p. ej., art. 20.3 de la Ley de Residuos 10/1998) y en el Derecho comparado (Suecia).

Sobre la base de previsión tan necesaria, tendría que plantearse la revisión de amplios aspectos del régimen local. Las competencias municipales merecerían ser tratadas de otra manera, por ejemplo, ampliando sustancialmente tanto la lista de las competencias garantizadas como la de las exigidas a los ayuntamientos. En los mecanismos de financiación cabría incluir, junto a los fundamentales tributos propios, que permiten canalizar más fácilmente la imprescindible responsabilidad de los titulares del poder ante los contribuyentes y votantes, otras fórmulas como la participación en impuestos estatales o una particular limitación de las transferencias condicionadas, para formar un fondo o una dotación genérica de los municipios desde los presupuestos del Estado y de las Comunidades Autónomas. Sólo unos municipios sólidos pueden beneficiarse de la aplicación efectiva del principio de subsidiariedad recibiendo traspasos de competencias autonómicas en materia de educación, sanidad, transporte, trabajo, acción social, vivienda, desarrollo rural y muchos otros. Quizá sería viable entonces el establecimiento de un amplio capítulo de servicios obligatorios que garantizara la igualdad real de todos los ciudadanos.

Finalmente, para evitar el riesgo de que la formación de grandes municipios pudiera acentuar en cada circunscripción el dominio de la correspondiente ciudad central sobre los restantes núcleos de población, sería muy importante articular cautelas de equilibrio interno en los nuevos municipios, haciendo compatible el objetivo de fortalecer la vida municipal con el mantenimiento de la diversidad local. Cabe pensar en la configuración de estatutos de concejo para los antiguos ayuntamientos profundizando en el modelo de las entidades locales menores, en la apertura de cauces sin- 
gulares de representación de estas realidades dentro de la organización del nuevo municipio, en el establecimiento de fórmulas comunitarias del tipo de los montes vecinales en mano común, etc. El resultado no debe ser el dominio de las ciudades medias sobre su entorno rural, sino la integración de todos los elementos territoriales en entidades capaces de desarrollar políticas públicas que permitan promover el progreso de las comunidades locales.

\section{BIBLIOGRAFÍA}

Albi, Fernando (1966): La crisis del municipalismo, Madrid, IEAL, $514 \mathrm{pp}$.

Albrekt Larsen, Christian (2002): "Municipal size and democracy: a critical analysis of the argument of proximity base on the case of Denmark", Scandinavian Political Studies, 25-4, pp. 317-332.

Aparicio Pérez, Miguel Ángel (2003): “Territorio y organización política”, J. Infante Díaz (ed.), Las comarcas de Aragón: territorio y futuro, Zaragoza, Gobierno de Aragón, pp. 143-155.

Burgueño, Jesús (2004): “El eterno debate sobre la reforma del mapa municipal. El caso de Cataluña", Revista de Geografía, 3, pp. 7-33.

Casassas, Lluís y Clusa, Joaquim (1981): L'organització territorial de Catalunya, Barcelona, Fundación Jaume Bofill, 326 pp.

Council of European Municipalities and Regions (2008): Balancing democracy, identity and efficiency. Changes in local and regional structures in Europe, Brussels, 94 pp.

Dahl, Robert A. (1971): "The city in the future of democracy", American Political Science Review, 61, pp. 953-970.

Dahl, Robert A. y Tufte, Edward R. (1973): Size and democracy, Stanford University Press, $148 \mathrm{pp}$.

Dexia Reasearch Department (2008): Sub-national governments in the European Union. Organisation, responsibilities and finance, Dexia, $656 \mathrm{pp}$.

García Álvarez, Gerardo (2005): “Las comarcas”, J.M. Carbonero (dir.), La intermunicipalidad en España, Madrid, Ministerio de Administraciones Públicas, pp. 71-92.

Hermenier, Helen (2008): "The quest for perfect territorial organisation: comparison across Europe", Council of European Municipalities and Regions: Balancing democracy, identity and efficiency. Changes in local and regional structures in Europe, Brussels, pp. 3-7.

Hertzog, Robert (2010): "Intermunicipal cooperation: a viable alternative to territorial amalgamation?”, P. Swianiewicz (editor), Territorial consolidation reforms in Europe, Budapest, Open Society Institute, pp. 285-307.

Hlepas, Nikos (2010): “Uncompleted greek territorial consolidation: two waves of reforms", P. Swianiewicz (editor), Territorial consolidation reforms in Europe, Budapest, Open Society Institute, pp. 45-74.

Houlberg, Kurt (2010): “Municipal size, economy, and democracy”, P. Swianiewicz (editor), Territorial consolidation reforms in Europe, Budapest, Open Society Ins102 titute, pp. 309-331. 
Illner, Michal (2003): “Procesos de descentralización y reformas en el gobierno de los países de Europa central y oriental”, Información Comercial Española, 809, pp. 117-134.

Izu Belloso, Miguel J. (1999): “Democracia municipal ¿sin autonomía local?”, Diario de Noticias, 15 abril 1999.

Izu Belloso, Miguel J. (2007): “El mapa local de Navarra”, Libro homenaje al profesor Francisco González Navarro. Organización y procedimiento administrativos, Thomson-Aranzadi, pp. 427-452.

Ladner, Andreas (2002): "Size and direct democracy at the local level: the case of Switzerland", Environment and Planning C: Government and Policy, 20, pp. 813828.

Loperena Rota, Demetrio (1988): “El mapa municipal ante la reforma del régimen local de Navarra”, Revista Jurídica de Navarra, 5, pp. 107-118.

López Ramón, Fernando: “Los servicios públicos propios de la provincia”, R. GómezFerrer (dir.): La provincia en el sistema constitucional, Madrid, Civitas, 1991, pp. 349-368.

Márquez Cruz, Guillermo (2010): “La desorganización administrativa en el Estado fragmentado", R. Rodríguez González (director), Territorio. Ordenar para competir, La Coruña, Netbiblo, pp. 137-181.

Martín Mateo, Ramón (1964): La comarcalización de los pequeños municipios, Madrid, Ministerio de la Gobernación, 108 pp.

Meligrana, John, ed. (2004): Redrawing local government boundaries: an International study of politics, procedures and decisions, Washington, UBC Press, $246 \mathrm{pp}$.

Ministerio de Administraciones Públicas (2005): Libro blanco para la reforma del gobierno local, Madrid, $116 \mathrm{pp}$.

Morell Ocaña, Luis (1972): Estructuras locales y ordenación del espacio, Madrid, IEAL, $251 \mathrm{pp}$.

Nieto, Alejandro (2008): El desgobierno de lo público, Barcelona, Ariel, 392 pp.

Pop, Daniel (2005): “Municipality size and citizen's effectiviness: Hungary, Poland and Romania”, G. Soós, V. Zentai (eds.), Faces of local democracy. Comparative papers from Central and Eastern Europe, Budapest, Kim Frazes, pp. 170206.

Roca Junyent, Miquel, president (2000): Commissió d'experts. Informe sobre la revisió del model d'organització territorial de Catalunya, Departament de Governació y Relacions Institucionals, 125 + XXXIX pp.

Rodríguez González, Román (2005): Territorio y gobierno local en España, un planteamiento de reestructuración por fusión como realidad necesaria, Madrid, CivitasThomson, $162 \mathrm{pp}$.

Salanova Alcalde, Ramón, director (2002): La comarcalización de Aragón (II), Zaragoza, Cortes de Aragón, 254 pp.

Sánchez Blanco, Ángel (2006): Organización intermunicipal, Madrid, lustel, 264 pp.

Sosa Wágner, Francisco y De Miguel García, Pedro (1987): Creación, supresión y alteración de términos municipales, Madrid, IEAL, $142 \mathrm{pp}$.

Swianiewicz, Pawel, editor (2010): Territorial consolidation reforms in Europe, Budapest, Open Society Institute, $341 \mathrm{pp}$. 
Velasco Caballero, Francisco, director (2010): Gobiernos locales en Estados federales y descentralizados: Alemania, Italia y Reino Unido, Barcelona, Institut d'Estudis Autonòmics, $727 \mathrm{pp}$.

Warren, Mark E. (2001): “¿Qué puede significar hoy la participación democrática?”, Ramón Máiz (ed.), Contrucción de Europa, democracia y globalización, Servicio de Publicaciones de la Universidad de Santiago de Compostela, vol. I, pp. 67-87.

Wollmann, Hellmut (2008): “Decentralization and territorial local government reforms between local democracy and operacional efficiency. Some comparative observations and conclusions in the European context", Council of European Municipalities and Regions, Balancing democracy, identity and efficiency. Changes in local and regional structures in Europe, Brussels, pp. 82-91. 